Portland State University

PDXScholar

6-1-1994

\title{
A Music Therapy Model for Counseling Corrections Clients
}

Karen Lee Kahle

Portland State University

Follow this and additional works at: https://pdxscholar.library.pdx.edu/open_access_etds

Part of the Education Commons

Let us know how access to this document benefits you.

Recommended Citation

Kahle, Karen Lee, "A Music Therapy Model for Counseling Corrections Clients" (1994). Dissertations and Theses. Paper 4767.

https://doi.org/10.15760/etd.6651

This Thesis is brought to you for free and open access. It has been accepted for inclusion in Dissertations and Theses by an authorized administrator of PDXScholar. Please contact us if we can make this document more accessible: pdxscholar@pdx.edu. 


\section{THESIS APPROVAL}

The abstract and thesis of Karen Lee Kahle for the Master of Science in Education: Counseling were presented June 1, 1994, and accepted by the thesis committee and the school.

COMMITTEE APPROVALS:

SCHOOL APPROVAL:
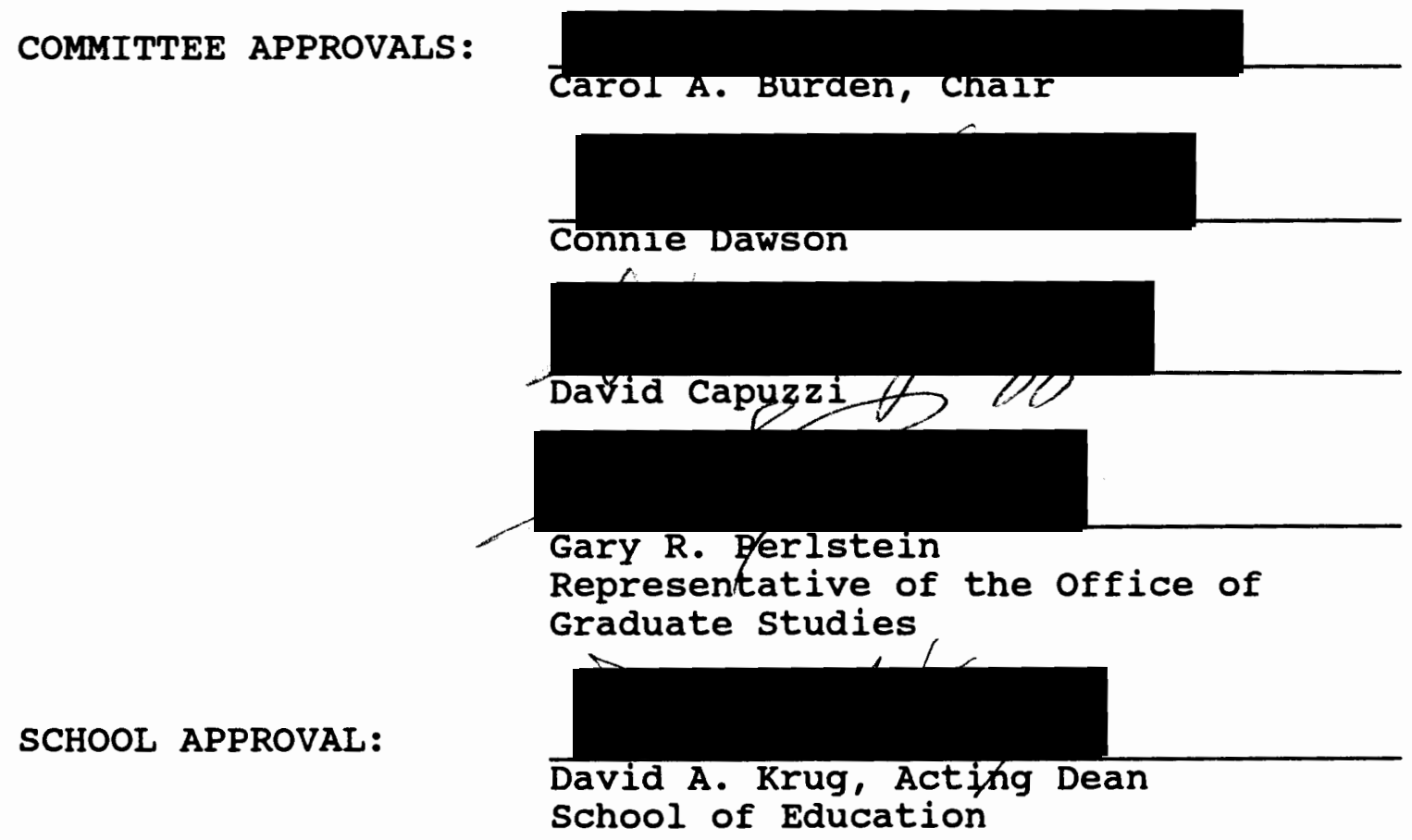

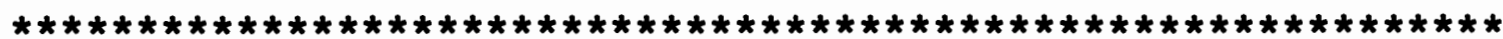

ACCEPTED FOR PORTLAND STATE UNIVERSITY BY THE LIBRARY

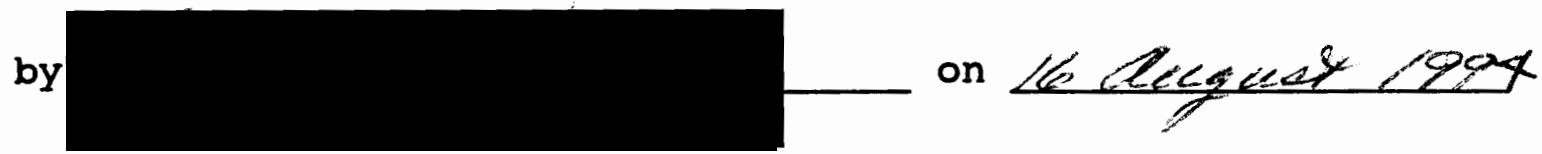




\section{ABSTRACT}

An abstract of the thesis of Karen Lee Kahle for the Master of Science in Education: Counseling presented June 1, 1994 .

Title: A Music Therapy Model for Counseling Corrections clients

The purpose of this thesis is to offer a music therapy model for integration into current counseling services available to corrections clients within the oregon prison system. Such a model was developed by reviewing existing literature and examining current therapeutic structure within the corrections system. The goal of this examination was to: (a) review the historical development and effectiveness of music therapy; (b) examine the elements of music and its effects on humans; and (c) investigate characteristics of the offender and provide an overview of client issues, treatment goals, and interventions of counselors working with inmates.

From the above data, issues significant to the corrections client were compared to treatment issues of populations where music therapy has been found to be effective. This comparative analysis was then used to 
develop a conceptual model of music therapy as an adjunct approach to counseling corrections clients.

Oregon's prison population continues to rise and the Department of Corrections is striving to implement programming aimed at reducing recidivism and facilitating behavior change on the part of corrections clients. Statistics show that many of oregon's prison inmates are repeat offenders which points to a need for more effective rehabilitative programs within the prison setting. The department's 1993-1995 strategic plan calls for expansion of institutional programming aimed at rehabilitation that includes counseling programs as well as treatment programs for drug and alcohol dependency.

Music therapy is recommended by this author as an additional counseling intervention to be utilized by counselors working with corrections clients. The characteristics of music therapy and its effectiveness with a variety of client populations make it a viable consideration for integration into the therapeutic experience of this challenging population. 


\title{
A MUSIC THERAPY MODEL FOR COUNSELING CORRECTIONS CLIENTS
}

\author{
by \\ KAREN LEE KAHLE
}

A thesis submitted in partial fulfillment of the requirement for the degree of

\author{
MASTER OF SCIENCE \\ in \\ EDUCATION : \\ COUNSELING
}

\author{
Portland state University \\ 1994
}




\section{ACKNOWLEDGMENTS}

This thesis is done, but from the insights I have gained and the hopes I see for tomorrow, my journey with music and therapy is just beginning. During my thesis life I have felt great euphoria about taking this path, but have also known great frustration and exhaustion Determination, joy, pain, anger, discomfort, curiosity, and awe are just some of the other feelings that I've encountered. For that, I suppose I have to thank the thesis endeavor, for I Iike to think this phenomenon has somehow taken me to deeper levels of compassion of connections as I pursue my work and play in the counseling profession.

Most importantly, the thesis experience and my future hopes would not have such meaning if not for the love and support of my family. My husband, Gregg; my daughter Alisha; and my son Dylan, I thank you and love you all so much.

Countless other individuals have made this accomplishment possible for me by providing a deep quality of support, encouragement, critical analysis, and humor, among other qualities. I cannot adequately thank all of those who have touched my life and helped make this project happen in the space provided here. I intend to offer a 
gesture of thanks to each of you that reflects the heartfelt support you have given me.

And of course, my deepest gratitude to my thesis chairperson and advisor, Dr. Carol Burden; and to committee members Dr. David Capuzzi, Dr. Connie Dawson, and Dr. Gary Perlstein. I put great thought and effort in trying to create a quality committee that could offer knowledge, hope, encouragement, and would also challenge me to keep stretching and asking questions. This committee provided that in a very big way.

I choose to end my acknowledgments by quoting a song called The Dance, written by Tony Arata:

Looking back on the memory of

The dance we shared 'neath the stars above

For a moment all the world was right

How could I have known that you'd ever say goodbye

And now I'm glad I didn't know

The way it all would end, the way it all would go

our lives are better left to chance

I could have missed the pain But I'd of had to miss the dance. 
TABLE OF CONTENTS

PAGE

ACKNOWLEDGEMENTS. . . . . . . . . . . . . . . ii

LIST OF FIGURES . . . . . . . . . . . . . . . vii

CHAPTER

I INTRODUCTION. . . . . . . . . . . 1

Background Information. . . . . . 1

Statement of the Problem. . . . . 5

Conceptual Framework. . . . . . . 7

Methodology . . . . . . . . 8

Terminology . . . . . . . . . 9

II REVIEW OF THE LITERATURE. . . . . . . . • 11

Origins and Effects of Music. . . . . 11

The Development of Music

Physiological and Psychological

Effects of Music. . . . . . . . 13

Pitch

Intensity

Timbre

Interval

Rhythm

Scientific Measurements of Music's

Effects............. . 17

Psychological Responses to Music:

The Individual. . . . . . . . . . 19

Communication

Identification

Association 
Imagination

Self-Expression

Historical Development of Music

Therapy . . . . . . . . . . 26

Music Therapy in Practice . . . . . 31

Handicapped Children

Developmentally Disabled

Rock Music as Therapy for ADD

Children

Music Therapy for Pain Relief

of Terminally Ill

At Risk students

Individuals in Long-Term Care Settings

Music Therapy as Part of

Chemical Dependency Programs

Evaluation and Summary. . . . . . 36

III DESIGN OF THE STUDY . . . . . . . . . . 40

Counseling the corrections client.. . 40

Criminal Behavior Due to

Criminal Thinking Errors

Control Theory

Transactional Analysis

Rational-Emotive Therapy

Reality Therapy

The Criminal's Self Image . . . . . 47

The Criminal and Drug Use... . . 51

Treatment Issues. . . . . . . . 52

Considerations for Counselors . . . 56

Treatment setting and Philosophy

Group and Individual Process

Evaluation and Summary. . . . . . 59

IV RESULTS . . . . . . . . . . . . . 62

Music Therapy Model for Corrections clients in the Prison setting... 62 
Salient Features. . . . . . . .

Assumptions About Music Therapy and the corrections client Population

Assumptions About Counselor Use of Music Therapy Approaches

structure of Proposed Model . . . . 65

Proposed Music Therapy Approaches . . 69

Improvisational Approaches

Listening to Music

Listening to New Age Music

Therapeutic Listening to Popular Music

Composing Music and Lyrics

Proposed Music Therapy Session

Format. . . . . . . . . . 87

Sample Lesson Plan

Listening to Music: Three Session Format

Evaluation and Summary. . . . . . . 92

V SUMMARY, CONCLUSIONS, RECOMMENDATIONS • • . 95

REFERENCES. . . . . . . . . . . . . . . . . . 98 


\section{LIST OF FIGURES}

FIGURE

1. Proposed Model for Music Therapy Integration
PAGE 


\section{CHAPTER I}

\section{INTRODUCTION}

\section{BACKGROUND INFORMATION}

What is music? Music is most often thought of as what we hear over the radio, in concert halls, or from musical instruments. Humans have been exposed to music since primitive times and almost any of us today can describe in some way the effect of music in our lives. One example of the power of music that many can relate to is how listening to a particular song can evoke strong personal feelings and affect one's mood, either positively or negatively. Anyone who has listened to or played music has experienced the range, depth and variety of feelings that can result.

What is the potential for music in mental health therapy? In a paper presented to the 1983 Annual Convention of the American Personnel and Guidance Association, two leaders in the music therapy movement maintained that, if we as a society and individuals were more attuned to poetry and music in our everyday lives, there would be less need for poetry or music therapy, or any other type of therapy for that matter (GIadding \& Mazza, 1983). Indeed, the effects of music and its importance to the health of the whole person can be traced back to ancient times. The Greek 
philosophers Plato and Aristotle both advocated the use of music to promote or produce particular moods (Peters, 1987). The Greeks applied music systematically to cure or prevent physical and mental disorders. They believed its effects on man's physical and mental state were predictable and measurable (Alvin, 1966).

As early as 500 B.C. Ancient Egyptians encouraged someone suffering with a mental disorder to pursue artistic influences and attend concerts and dances. The belief was that this could enable the person to release feelings and, in time, be made whole again (Fleshman \& Fryear, 1981). As the Greeks and Egyptians employed drama and music as a healing tool, early Hebrews utilized music and lyrical verse to develop integrity and healthy relations in its people (Gladding, 1985).

A more modern though remarkably similar rationale put forth by noted psychologist Dr. Carl Rogers (1957) is that through the use of music a patient can experience connectedness of mind and body. For example, anorexics have distorted views of their bodies or do not acknowledge or use their bodies in a positive way. Music therapy can tackle a dilemma as this on the following five fronts:

\footnotetext{
1. Energy and Process: The therapy is participatory; it requires action.
}

2. Focus: The client can see goals more clearly. 
13. Creativity: It enlarges the client's universe by adding or uncovering new dimensions and encourages a sense of playfulness and joy.

4. Practical: A client can establish a new sense of self and can practice novel and adaptive behaviors.

5. Concreteness: The client can conceptualize and duplicate activities that are beneficial.

Another perspective offered by music therapist Mary Priestley (1975) about the healing powers of music speaks to its ability to communicate. She describes music as a therapeutic medium that can penetrate where all other communication fails. Deeply buried memories and emotions that are paralyzingly frightening and painful cannot always be translated into words. In her experience, music therapy with patients has been a method to release, express and contain such emotions.

Music's effect on humans is highly complex, particularly with regard to rhythm, which is considered the main component of music. In everyday human activity, there is rhythm in rest and activity, sleep and wakefulness, eating and appetite, bowel and bladder function, respiration and heartbeat, speech, gait, sexual intercourse, and hormonal patterns (Giaccobe, 1972). (In addition, music therapy connects with subconscious, emotional, and physiological aspects of a person; it is not connected only with the rational side of consciousness (Boyum, 1978). It 
has been exceptionally effective with hard to reach clients and diverse client populations and can be utilized in many different ways, depending on the problem or issue at hand (Santiago, 1969).

Although knowledge and perceptions about music's complexities and powers date back to ancient times, the first truly scientific studies on music therapy were less than 100 years ago by Drs. Binet and Courtier in 1895 (cited in Schoen, 1940). They found that loud music stimulated one's heartbeat and soft music acted as a sedative.

since then, numerous studies have tried to determine the effect of music with various client populations suffering various types of problems. A brief overview of these studies is as follows: (a) correlation of student receptiveness and music tempo in elementary students (Kuhn \& Booth, 1988); (b) music as a motivator for at-risk students (Duerksen \& Darrow, 1991); (c) counseling the talented and gifted student through the use of music and dance therapy (Kenny, 1987); (d) music therapy and personality change in autistic children (Nordoff \& Robbins, 1965); (e) music therapy as part of chemical dependency treatment (James \& Townsley, 1989); and (f) using music therapy as a tool for dealing with anger (Meeker, 1985).

A review of the literature suggests that music therapy interventions can address diverse issues and reach a variety of populations. Particularly noteworthy is its ability to 
reach the challenging, resistant, and/or hard to reach client. Music therapy seems to offer a new dimension to healing the emotionally troubled client. This is of particular significance to counselors working with clients who present special challenges.

\section{STATEMENT OF THE PROBLEM}

The corrections population is one such example of a challenging population and professionals within the corrections field are constantly examining ways to address and reduce criminal behavior. In oregon, the prison population continues to rise and statistics show that many are repeat offenders indicating a need for more effective rehabilitative (or habilitative) programs within the prison setting.

Traditionally, rehabilitation has not been considered the goal or purpose of prison incarceration. Rather, prison time is a punitive consequence experienced by an individual who has been convicted of breaking the law. A person is sent to prison to serve his or her sentence, thereby paying one's debt to society. Historically, this approach has not been effective.

An analysis of Oregon's offender population shows that $50 \%$ of the current prison population consists of newly convicted felons and 50\% are offenders whose parole or probation has been revoked. of those being admitted to 
prison, only $18 \%$ were newly convicted felons and $82 \%$ are offenders revoked from parole or probation, some of whom were also convicted of a new offense (Hall, 1993).

The Oregon Department of Corrections (ODOC) is addressing this problem of recidivism. Its 1993-1995 strategic Plan calls for expansion of institutional programming aimed at rehabilitation. The range of programs highlighted in the plan includes treatment programs in the area of alcohol and drugs and in self-accountability and responsibility (Hall, 1993).

Further, the plan notes that while a perception exists that public safety is defined by the number of police on the streets or the number of jail or prison beds, it is ODOC's belief that real public safety is better defined by what is done to change offender behavior (Hall, 1993). This includes the use of innovative therapy programs where both established and new mental health interventions are being explored.

The purpose of this thesis is to examine music therapy interventions from a review of existing literature and research and propose a model for integrating music therapy into existing counseling approaches within the prison setting. This author found no literature regarding the use of music therapy with prison inmates, yet it seems a timely and relevant topic to explore. Everyone in this society is impacted by the effects of crime in some way. Exploring 
methods for reducing crime, which includes examining and expanding counseling efforts to the perpetrators of crime that can effectively confront a client's criminality and facilitate emotional change, are of great significance.

\section{CONCEPTUAL FRAMEWORK}

Counseling the corrections client offers a myriad of challenges. Counselors who serve a challenging population such as this employ a range of theoretical orientations and use a variety of therapeutic tools. The characteristics of music therapy indicate it could be a viable intervention that can heighten the counselor's effectiveness. Music therapy applications that are recommended for corrections clients in this thesis are intended to enhance what the corrections therapist already brings to the counseling experience. Counselors providing treatment services to inmates need to possess certain characteristics and skills. Basic therapy qualities should include the following: (a) a stable self-concept; (b) emotional maturity; (c) an understanding of the concept of criminality, criminal thinking and its manifestations; (d) non-judgmental attitudes and beliefs about the corrections client; and (e) the ability to analyze and accurately diagnose client issues and problems (Gladding, 1988).

It is expected that the counselor, in addition, has a primary theoretical orientation to counseling with specific 
interventions that are congruent with his or her particular frame of reference. Integration of music therapy interventions would serve as a complement to such an orientation. For example, a behaviorist could use specific music interventions to elicit behavior change, whereas a cognitive therapist might use music as a diagnostic tool in obtaining information about a client's thinking patterns and beliefs. Psychoanalytic therapists could detect unconscious conflicts through the use of music, or family systems therapists could use music interventions as a safe way for family members to express painful emotions to each other. Given the range of modalities in which music therapy could be used, it has many strengths as a therapeutic intervention. It also appears to be one that lends itself to integration into existing interventions based on other counseling theories, be they cognitive, behavioral, or psychoanalytic in nature. It seems to be an approach that can complement and enhance other therapeutic work and can sometimes succeed where more traditional interventions have failed.

\section{METHODOLOGY}

To gain understanding and insight into how music therapy could be utilized in providing therapy to inmates and offer a conceptual model for integration into the 
existing therapeutic structure, this thesis reviews existing literature to do the following:

1. Review the historical development and effectiveness of music therapy.

2. Examine the elements of music and the effects on humans. Specific elements that define music (rhythm, tempo, pitch, harmony, melody, etc.) are identified that have been substantiated as having beneficial effects on the body and have the ability to elicit changes in mood and feelings.

3. Investigate characteristics of the offender and provide an overview of client issues and the treatment goals and interventions of counselors working with inmates.

4. From the above data, issues significant to the corrections client are compared to treatment issues of populations where music therapy has been found to be effective. This comparative analysis serves as the foundation for a conceptual model of music therapy as an adjunct approach to working with corrections clients.

\section{TERMINOLOGY}

Music therapy is a vast field and its uses and integration into the counseling profession are still evolving. The concept requires clarification to provide a reference point in studying its elements and applications. Music therapy is the controlled use of music in the treatment, rehabilitation, education and training of adults 
and children suffering from physical, mental and emotional disorder. Since it is a function of music in which music is not an end in itself, its therapeutic value is not necessarily related to the kind of music used, nor to a standard of musical achievement. Its effects are primarily due to the influence of sound on an individual (Alvin, 1966). Music therapy is a professional intervention with therapeutic, non-musical goals. It is not to be confused with music education or enrichment, which possess different goals and are not interchangeable with music therapy (Beaulieu, 1987).

Two collaborative terms used in this study also require clarification. These are corrections client and inmate. In different settings these terms may have distinct meanings from one another. For purposes of this research, both are synonymous to an individual serving a prison sentence within a correctional institution.

The term counselor needs further elaboration, as well. The term corrections counselor is one that identifies many staff members within a prison who do not necessarily provide mental health counseling or therapy. For that reason, corrections counselor is not a term to define a mental health counselor. The terms counselor and therapist are referred to when identifying a mental health professional practicing a theoretical orientation and approach to counseling. 
REVIEW OF THE LITERATURE

ORIGINS AND EFFECTS OF MUSIC

"Viewed historically, music as therapy is both ancient and young; its roots deep and its branches ever growing" (Boxil1, 1987, p. 1).

The word music applies to such a variety and complexity of experiences. To better understand at a basic human level why and how we can use music as a therapeutic agent, one can take a historical look and examine the origins and effects of music. The substance of sound has always been part of the conscious world of humans and has been interpreted or used according to the kind or state of civilization existing at that time. Such a historical survey helps define the relationship between the origins of sounds and the development and use of music today (Alvin, 1966).

\section{The Development of Music}

The development of music began when people consciously organized natural sounds occurring around them, and combined this processes with imitation and repetition. However, this creative process was believed to be of supernatural origin. In all known early civilizations, the creation of music was 
thought to come from some divine origin and was not the creation of human beings (storr, 1992).

In 1909 Charles Darwin (cited in walter, 1957) proposed a biological theory for the creation of music as part of his theory of evolution. He explored the evidence and significance of expressive sounds produced by animals, especially birds. He noticed the various emotions contained therein, such as distress, fear, anger, triumph or mere happiness. In addition, he noted that the true songs of most birds served as a charm or as a call note to the other sex.

It is important to include the role of musical instruments in the development of music. As with sound, certain musical instruments during the primitive ages were thought to possess magical power and believed to be inhabited by or symbolic of a supernatural being. In some countries drums were believed to be of magical origin, sacrifices were made to them, and they were even offered food. Further, the musical instruments used by the magician of a tribe during certain rites were a symbol of his power. He often wore rattles, adding to the dramatic effect he presented with his gesticulations and his attire (Alvin, 1966).

From the perspective of music as therapy, it is noteworthy that the primitive as well as modern player has always identified with his or her instrument. It is an 
extension of his or her body and through this relationship, the musician transforms one's psychomotor impulses into sound and expresses them through the musical instrument. Such manipulation of an instrument also demands conscious control of movement in time and space, and obedience to certain acoustical laws. This process alone has a wellknown therapeutic value (Alvin, 1966).

\section{PHYSIOLOGICAL AND PSYCHOLOGICAL EFFECTS OF MUSIC}

An effective approach to this subject may be to examine how sound affects the mind and the senses. Extensive literature now exists outlining the functional specialization of the two hemispheres of the brain. Evidence shows that the right and left hemispheres speak and understand two different languages (Watzlawick, 1978). Within the dominant hemisphere exists our complete language system and this hemisphere operates through a framework of definition, logic and rational analysis. It speaks and understands a language of science, explanation, and interpretation. Verbal therapeutic approaches speak to this hemisphere of the brain (Brydon, 1979).

The nondominant hemisphere specializes in visualization. It speaks and understands a language of totality and synthesis, not the analytical language of the dominant hemisphere (Brydon, 1979). Research points to three powerful ways to access and communicate with the 
nondominant hemisphere, which are music, metaphor and visualization (Bandler \& Grinder, 1975). The implications of this in considering the use of music for therapeutic intervention are significant. To be able to access and speak to the nondominant hemisphere is of great importance in the process of change; the process of change is a central aspect of therapy (Watzlawick, 1978).

There are some distinctive qualities of music, too, which stand out and affect us as listeners and require more in-depth discussion. These qualities are as follows: Pitch; (b) Intensity; (c) Timbre; (d) Interval; and (e) Rhythm.

\section{Pitch}

Pitch refers to the frequency of the music, or the number of vibrations in a given sound. Rapid vibrations produce a strong nervous stimulus whereas slower vibrations tend to relax (Watson, 1987). It affects humans at a purely physical level and in a rational way (Alvin, 1966).

\section{Intensity}

Intensity refers to the amplitude of vibrations, or volume. For example, loud music has considerable "carrying power." It is dominating and coercive and excludes other sounds. It may give the listener the feeling of being "protected." On the other hand, soft music creates a more intimate and serene feeling and atmosphere (Watson, 1987). 
The intensity of music can go from the nearly inaudible to the deafening. It plays a major role on music's impact and can sometimes itself be a means of gratification. A case in point is if an unsophisticated listener prefers symphonic to chamber music, the reason may be due to its large volume, not because of any interest in the musical value of the composition (Alvin, 1966).

Timbre

Timbre is also known as tone color. Timbre, or tone color depends on the harmonies in the music, which then evoke associations in the mind of the listener at a nonintellectual level (Watson, 1987). Some propose this musical quality to be one of the most suggestive elements of music. Our vocabulary is not expansive enough to accurately capture the meaning of what takes place, therefore the reference to "color" to depict one of the most important elements contained in musical sound. Tone color is of great psychological significance because of its associative power (Boxill, 1987).

Tone color is a non-rhythmical, purely sensuous element of music that produces in the listener a pleasurable nonintellectual impression against that he or she does not erect a defense mechanism. This can be observed by the effect produced when listening to certain pieces by chopin or Debussy, by the low notes of the flute, or the sound of the celesta (Alvin, 1966). 


\section{Interval}

closely related to pitch, interval refers to the distance between notes and results in melody and harmony. certain combinations of notes may seem more attractive, but often such an evaluation is largely influenced by cultural factors (Watson, 1987).

The combination of sounds into a specific series of intervals can result in either a pleasant or unpleasant effect to the ear. Before coming to a harmonious conclusion a musical composition may encompass many inconsistencies which are to the individual either stimulating, irritating, or disturbing. A person may even connect powerfully to some sense of dissonant interval which reflects that person's inner state. But, whatever happens in the course of the musical development, there is, at the end, a solution (Alvin, 1966).

\section{Rhythm}

Rhythm is the dynamic element in music; the time pattern within a certain speed. "Standard" rhythm is roughly the same rate as the heartbeat, around 70 to 80 beats per minute. Rhythm relates strongly to different human emotions. Some rhythmic patterns in music have the ability to sweep us along with their momentum and to elevate us to a new level of sensory awareness. Such forms of music, as noted by Carl Seashore (cited in Diamond, 1979) in his 1967 study of the psychology of music produce "a mild 
form of ecstasy" or "a feeling of freedom, luxury and expanse." By contrast, Seashore maintains that other rhythmic patterns, especially the anapestic stopped beat of some forms of rock music (e.g., da: da: DA), may have a draining or weakening effect on the human organism. Such rhythms might result in a loss of symmetry between the two cerebral hemispheres of the brain and in short, can throw the entire body into a state of disturbance.

on the other hand, rhythm is symbolically linked to will power and self-control. In this context, it is orderly, physically strong, and creates an exhilarating effect for the listener and performer alike. This type of rhythm is a most vital element in the music of such composers as Beethoven or Dvorak (Alvin, 1966).

\section{SCIENTIFIC MEASUREMENTS OF MUSIC'S EFFECTS}

The origin and development of music have produced a profound curiosity and interest about its scientific effects on individuals. In studying these effects, it is extremely difficult to scientifically separate the physiological and psychological changes that take place. In looking at this phenomenon, philosophers, physicians and musicians have oscillated between two major schools of thought. The first is the belief that music primarily affects the emotions and creates moods which in turn act on the body. The second theory is that the process works in reverse, from the 
physiological to the psychological. Most of the time the two processes react on one another (Alvin, 1966).

Another integral piece in exploring the effects of music is the recognition that throughout history, one's responses to music have been very similar and influenced by the same factors which include the following: (a) one's physical receptivity to sound; (b) one's innate or acquired sensitiveness to music, and; (c) one's current state of mind at the time. In addition, conditioning due to prejudices, environment, education and other non-musical factors play an important part in these responses, as well. An individual also may respond most meaningfully, to music of his or her culture, which conveys to him or her some meaning and emotions. In therapy the best music of its kind is likely to be the most effective, since any function is best fulfilled by the best suitable means. Best in this instance is defined as what succeeds, not what is "good" or "bad" music. In other words, it refers to the ability to elicit the most meaningful response from the client (Alvin, 1966).

with a few exceptions, attributed mainly to an individual's mental or nervous state, patients usually react consistently to the elements of music, to their dynamism, and to their sensory, emotional and intellectual appeal. one can expect predictable reactions to music possessing conventional characteristics such as gaiety, sadness, excitement, or calm. Some exceptions can be found, however, 
such as in some cases of schizophrenia (Alvin, 1966). Another important phenomenon is the unexpected incongruent emotional reactions to certain music. These are ones that are not due to illness but to the association of the music with past memories. An example would be a client becoming distressed when listening to a gay, lighthearted tune because it reminds him of a distressing and painful event in his life (Watson, 1987).

The understanding of the nature and causes of individual responses to music is indispensable to the application of music therapy, since it points to the need to provide an individualized treatment plan based on client/therapist goals. Aiming toward certain results may require vastly different techniques. A major objective is to observe the client's response to certain musical experiences and use these responses as an aid to the diagnosis or treatment of the disorder. Another objective is to deliberately provoke certain reactions, then control and channel them toward a specific therapeutic aim (Boxill, 1987).

\footnotetext{
PSYCHOLOGICAL RESPONSES TO

MUSIC: THE INDIVIDUAL
}

The psychological responses to a musical experience depend on the ability of the listener or performer to communicate and identify with the music. Imagery, association or self-expression to be found in the music is 
what is already in the individual, not yet expressed (storr, 1992)

Music works at id, ego and superego levels and its abilities are quite diverse. The following examples describe some of those abilities: (a) It can stir up or evoke primitive instincts; (b) it can help strengthen the ego state, and has the ability to simultaneously release and control the emotions; (c) it can give a sense of purpose to the listener and/or the performer; (d) it can refine and heighten certain emotions and satisfy desires through high aesthetic and spiritual experiences. In short, music can help an individual express his or her whole range of experiences because of its relationship to the three levels of the human personality (Alvin, 1966).

When using music therapeutically, the major psychological effects of music on the individual may result in the following conditions, each of which merits attention. These are communication, identification, association, imagery, self-expression and self-knowledge (Alvin, 1966).

\section{Communication}

An almost universally stated definition is that music is a means of communication. In this statement the foundation for the tremendous therapeutic value of music can be found, since illness is the result of a breaking up of communication in some form (Alvin, 1966.) 
We were not born to live in isolation; as individuals, we need the presence of others to fulfill physical and psychological needs. In addition, human survival and development have always depended on one's sense perception and intelligence, enabling one to integrate with the surrounding world. One tragedy of sickness is that it fosters isolation and/or insecurity and impairs contacts and normal relationship with the environment (Alvin, 1966).

\section{Identification}

Anytime a person has imitated and/or interpreted previously heard data, he or she has then become part of a world of sounds to which he or she has now given a realistic or symbolic meaning.

As we listen to imitations or simulations of sound and music, we can identify with particular thoughts, feelings and moods. These can range from anger and courage to pain and grief. We see from actual experience that listening to such imitations evokes a change in our own soul, be it pleasure or pain (Alvin, 1966).

A person identifies with music to the extent with which he or she can give one's own interpretation. similarly, a person can also identify with a composer if the music reflects the composer's personality or life. For example, Schumann (cited in Alvin, 1966) described his schizophrenic tendencies in the dual portraits of Florestan and Eusebius; Smetana's "Quartet of My Life" is an accounting of his own 
life in which even his tragic attack of deafness is realistically rendered by a long piercing note.

A meaningful perspective in looking at this material with regard to using music as an emotionally sound therapeutic intervention might be to see that the personal interpretation of the listener or performer amounts to an act of re-creation of some kind and can answer an individual's need for creative activities. Since music can express human characteristics in musical terms, it can also reveal some personality disorders. A case study of a middle-aged patient at an overseas psychiatric social club outlines the client's description to his therapist in purely musical terms his search for his lost personality. The client was an adequate amateur pianist, and though he could not read or write music, he had a talent for improvisation by ear (Alvin, 1966).

This particular patient told his therapist through musical means that he could not find "his own style"--style here meant personality. Every day he reported how he composed in a different style; something that distressed him deeply. He had no record of the previous improvisations, but day after day he went on trying to find his own self in music. The musical treatment intervention to this was to ask the client to see that each of his improvisations be recorded and dated; a number of them were then played back to help find a common theme or center among the various 
music elements. Through this process and the resulting interpretations, the patient was able to discover his musical style and importantly, to integrate his own true personality (Alvin, 1966).

\section{Association}

Music is so overwhelmingly in the functions and places of everyday life and in special events that almost every human being is exposed to it in various levels and in various ways. As humans, we associate with it in related and actual moods, but it also triggers our association with past experiences. Music also has the power to recall perceptual sensations, such as smells, touch or color (Storr, 1992).

To illustrate the associative powers of music, interviews were given to various people in the British Broadcasting Company's "Desert Island Discs" program regarding their choice of musical selections (Alvin, 1966). This event revealed that the music's effects were due in large part to its association with people, friends or family and various life experiences. Rarely did an interviewee state that the choice was prompted by purely musical reasons. This incident is cited because the success or failure of music therapy depends on human as well as musical factors of relationship. For example, an assessment of the patient's response to music should include what could be called a "musical history." 
Imagination

If music can provoke associations with real life experiences, much of its evocative power falls in the realm of the imaginary or extra-sensorial. Music, for instance, made up of elusive impalpable sounds can express a world of unreality and fantasy, of escape and dreams. One has a need for such experiences; this need can be fulfilled when one is well balanced and able to distinguish between reality and fantasy. If one's mental balance is impaired, the value of such an escape is questionable, through musical means or any other (Alvin, 1966).

Imagination is one of the most creative human faculties when it is kept within reasonable bounds. Since music is wordless, few limits stand in the way of its evocative and imaginative power. Falling under the heading of imagination includes such activities as daydreaming, mental flights of fancy, and mental imagery of many kinds: realistic, fanciful, dreamlike, fantastic, mystical or hallucinatory (Alvin, 1966).

In short, music can provide a bridge between the real, and the unreal, the conscious and the unconscious. This characteristic of music has been used in many situations. The lullaby provides a transition between wakefulness and sleep. It can also bring to light to an adult a long forgotten memory. It is not surprising, then, that music has been associated with the world of dreams since primitive 
times. Healing music often comes through a dream. It appears that music can provoke in the mind kinesthetic images of movement that feel real. The listener to music may be asleep and dreaming but also be experiencing the feeling of performing physical actions. It is possible, then, to see music and dreams as an imaginary substitute for action or movement (Alvin, 1966).

\section{Self-Expression}

Music that can evoke, associate, and integrate is for that very reason an exceptional means for self-expression and emotional release. This may not be the primary function of music, but the primary function may not necessarily be the most important (Alvin 1966).

Music is an intervention that can address the need for self-expression. It can facilitate this self-expression by bringing into consciousness deep-seated emotions. It then can provide the outlet necessary to appropriately discharge of the emotion. This, by the way, is a function that music has fulfilled since time immemorial. The Greeks called the purging of the emotions the cathartic effect that some music made on the listener, thereby restoring him to a harmonious state (Alvin, 1966).

If music can help the listener to explore and discover one's inner self through this deep psychological process, then it is a logical premise that musical activities can help the performer to acquire or develop self-knowledge and 
knowledge of others. Music making is a shared experience that cannot be pursued or enjoyed without self-knowledge and an ability to communicate (Alvin, 1966).

\section{HISTORICAL DEVELOPMENT OF MUSIC THERAPY}

Theoretically, the basis for modern music therapy is still evolving. Although the field of modern music therapy is still in its infancy, history shows that the use of music for healing was a very ancient practice. Music for healing was believed by primitive cultures to originate from magic, supernatural, or spiritual forces. Later cultures adopted a more rational attitude about the role of music in healing. Evidence shows that in ancient Greece the use of magical or religious customs was utilized side by side with many of our modern ideas on health and disease not connected with magic or religion. Apollo himself presided over music and medicine, perhaps symbolic of the interrelation of the two disciplines (Alvin, 1966).

Plato (cited in Scott, 1900) advocated the use of music as the most powerful means to reach the inner places of the soul, and when in that space, music fastened itself and imparted grace and well-being. He even linked music as a means to maintain the moral welfare of the nation (cited in Gammond, 1970).

Aristotle (cited in Scott, 1900) shared this opinion. He wrote that emotions of any kind are produced by melody 
and rhythm; thus through music one could become accustomed to feeling the right emotions. Music according to Aristotle had the power to form character and the various kinds of music could be distinguished by their specific effects on character. One, for instance, might work in the treatment of melancholy, another might encourage self-control, yet another might be engaged to promote enthusiasm. This therapeutic approach continued in Roman times, as well, but the fall of the Roman Empire also saw the demise of a rational conception of music therapy (Alvin, 1966).

During the Dark Ages the practice of medicine was kept alive primarily in Alexandria and passed into the hand of the Arabs in the countries they occupied in southern Europe. Most Greek medical texts were buried in European monasteries for several centuries and the medical work of the Greeks and Romans practically disappeared. The general attitude toward illness was mainly influenced by Christian beliefs. Music played a part in this time of healing, but was seen as a spiritual relief to illness, an idea accepted widely within the Church (Alvin, 1966).

The Renaissance was one of the most dynamic and creative periods of human history. The fields of medicine as well as music saw tremendous positive changes and both were able to affect people in society. For one, a new discovery of anatomy began to dominate the centuries that provided a rational conception of the mechanism of his body. 
This opened the door to modern scientific medicine based on observing phenomena that could be assessed in terms of causes and effects. This advance influenced all means, including the use of music in medicine (Schullian, 1948).

Gradual changes of attitude were now taking place toward music, which is of tremendous importance to the field of music therapy. Music was beginning to be seen as an important means of individual self-expression and of communication between composers, performers and the listeners. Furthermore, the context where this music was shared and the elements put forth were increasingly significant. From the seventeenth century onward, the therapeutic value of music was looked at in terms of physiology and psychology more than from the Greek philosophical and ethical angle (Alvin, 1966).

Within the United States, the evidence suggests that the public press introduced the idea of using music as an adjunct to medicine in the late 18th century. In fact, though, the practice of music for healing purposes dates back to use by the American Indians (Schullian, 1948).

The American Indians used two methods to treat illness in the early days that are still used today. One method involved treatment provided privately by a tribal doctor or medicine man. The other consisted of a public ceremony that was conducted by many doctors, attended by many people, and an event that would often continue for several days. With 
both methods, music was considered a crucial component and involved singing and the use of rattles, drums, and other instruments (Schullian, 1948).

These methods were seen and described by white men, and studies of the songs were made possible with the invention of the recording phonograph in about 1890. The studies showed consistent song formulas and rhythms, and similarities were also discovered between tribes that were widely separated geographically (Schullian, 1948).

In the non Native American culture, ideas were publicly generated and exploration was taking place regarding using music therapy to treat emotional disorders. In 1789, the Columbian Magazine printed an unsigned article, "Music Physically considered," which contained some basic ideas that remain at the core of modern music therapy practice (Gfeller, 1987). over the years, these ideas were debated and explored, but it was not until World war II that music therapy was pushed into greater prominence as a treatment modality. It was clear that veterans of the war needed therapeutic treatment, and music became a valuable intervention toward this end. The field continued to develop and has grown to encompass a variety of settings, including psychiatric centers and hospitals, outpatient treatment centers, special public and private schools, and community and private clinics (Boxill, 1987). 
With the growth of the field came the need to develop standards for the education and training of music therapists. The first academic program to train music therapists was developed at Michigan State University in 1944, and more have followed. Other highlights in the evolution of music therapy include the formation of the National Association for Music Therapy in 1950 (Heller, 1987), the creation of the Joumal of Music Therapy (JMT) in 1964 (Gfeller, 1987), and the creation of the American Association for Music Therapy in 1971 (Boxill, 1987).

Professional therapists practicing music therapy as a primary modality for treatment use a variety of musical approaches to achieve the following goals: (a) to facilitate interpersonal relations, (b) to encourage growth and development, (c) to work toward the attainment of selfactualization, and (e) to assist an individual's healthy functioning in society. In practice, it is a dynamic process of therapeutically based musical experiences generated in order to attain long and short term treatment goals (Boxill, 1987).

The education and training for music therapists is multidisciplinary in approach. It includes course work in musicianship, behavioral sciences, and theories rooted in psychiatry and psychotherapy. Educational curricula are designed so potential music therapists can become competent in the following areas: (a) music foundations, which 
includes music theory and history, composition and arrangement, and performance and improvisation; (b) clinical foundations, which encompasses dynamics of therapy, the therapeutic relationship, procedures, and terminology; and (c) music therapy, which focuses on foundations and principles, assessment, treatment planning, implementation, evaluation, interdisciplinary collaboration, and supervision and administration (Boxill, 1987).

overall, in surveying music therapy professionals currently in practice, the general consensus is that the theoretical foundations of music therapy continue to be formulated and new possibilities put forth in the form of treatment approaches and types of clients served. Also emerging is information and approaches with music that can be adapted and utilized by therapists where the primary theoretical orientation is one other than music (Bruscia, 1987).

\section{MUSIC THERAPY IN PRACTICE}

Today, music therapy is serving a wide variety of populations as either a primary or complementary modality in mental health or psychotherapeutic treatment. Some of the ways in which music therapy has been utilized are discussed here. 


\section{Handicapped Children}

This population was one of the first to benefit from the therapeutic effects of organized music therapy . Regarding client need, even the most severely handicapped person has normal basic needs for love, acceptance, security and success. Each of these individuals must also find a means of self-expression at his or her own level. Under these circumstances, music may be the only way one can realize the self (Alvin, 1966).

Music therapy with the handicapped can be used to achieve the following therapeutic goals: (a) awaken perceptual awareness; (b) assist in the development of auditory discrimination and motor control. Another benefit of music therapy is that it can be adapted to make the best of any ability a child or adult possesses, and can suit any mental, emotional or physical handicap (Nordoff \& Robbins, 1965) •

\section{Developmentally Disabled}

Boxill (1987) has completed an exhaustive amount of work and treatment interventions for the developmentally disabled using music therapy as a primary modality. Since 1975, she has specialized in the treatment of developmentally disabled persons through the use of music therapy and presents an innovative approach to music therapy for persons in the five categories of developmental 
disabilities: mental retardation, autism, cerebral palsy, epilepsy, and other neurological impairment.

Treatment strategies and specific music therapy interventions are used to address the four major problem areas presented with this population: (a) mental deficits; (b) maladaptive behaviors; (c) physical dysfunctions; and (d) emotional disorders. Modes of therapeutic music activity include but are not limited to singing/chanting, instrument playing, and music/movement (Boxill, 1987).

other studies and therapists have contributed music therapy interventions for this population, and treatment has been found to be effective in managed care as well as school settings (Nordoff \& Robbins, 1965).

\section{Rock Music as Therapy for}

\section{ADD Children}

A 1986 study conducted at the oregon Health Sciences University showed initial promise with using rock music as an adjunctive therapy for children suffering attention deficit disorder. It appears such therapy could provide additional supportive management of the condition and could be administered without training. Results of the test indicated a statistically significant reduction in the number of motor activities during music periods within the test sessions (Cripe, 1986).

It appears there is a multiplicity of levels of the ways in which music can treat varying physiological and 
emotional conditions and more studies are currently underway examining this feature of music therapy. The appropriateness of rock music may be inappropriate or ineffective for several disorders, yet extremely effective for others (Bruscia, 1987).

\section{Music Therapy for Pain Relief} of Terminally Ill

A 1985 experimental research study showed that music was effective as an intervention tool with the terminally ill (Curtis, 1986). This project, coupled with previous research regarding music therapy and pain management, suggests that the specific use of sound and music can have an analgesic effect and can also serve as a relaxation agent. This is of value to the terminally ill patient as the prominent emotional states to be addressed include anxiety, fear and anticipation of pain, uncertainty, low self-esteem, fear of death, self-absorption, and depression.

Other specific music and creative arts therapies currently being explored for use with the terminally ill include guided imagery with music, the effects of music in conjunction with the therapeutic personality, and muscle relaxation paired with music (Beaulieu, 1987).

\section{At Risk Students}

Music therapy has been found to be helpful with at risk students in providing motivation through specially planned music therapy activities. The activities are designed to 
address the following risks characteristic of at risk students: (a) lack of self-discipline and motivation; (b) not learning effectively; (c) alcohol and drug abuse; and (d) focus on rudimentary survival skills (Duerksen \& Darrow, 1991).

Components of programs utilizing music therapy with at risk students include evaluation, treatment intervention, appropriate liaison work between therapists and county, school, state and other impacted organizations, and traditional as well as creative arts therapies (KalishWeiss, 1989).

\section{Individuals in Long-Term}

\section{Care settings}

Expressive therapies such as art, music and dance have distinct characteristics that are necessary for working with older adults in long-term care settings. Such expressive activities in the long-term care environment promote creativity, self-expression, communication, and understanding of oneself (Bell, 1987). This can be particularly empowering when the purpose of the activity is to focus on the therapeutic process of the art or music making. Such a process oriented approach has yielded significant increase in clients' social skills and communication, increased social contact and decreased depression (Palmer, 1985). 
Music Therapy as Part of

Chemical Dependency Programs

Experimental research has shown that music therapy can contribute to comprehensive treatment programs for chemical dependency. One of the prime characteristics of the creative arts approaches (including music) that influences its effectiveness is its experiential nature, something that combines well with education geared to clients around chemical use and abuse (Ragghianti \& Glenn, 1991). The activity nature of the therapy also increases the potency of insight gained in the counseling sessions and discussion groups. Further, the techniques can be transferred to reallife situations (James \& Townsley, 1989).

\section{EVALUATION AND SUMMARY}

Music therapy is a therapeutically sound process that facilitates the emotional healing of a client by using musical experiences and relationships. As a modern treatment modality, it is in its early stages of development, but its beginnings can be traced to ancient times when music was being utilized to treat both physical, mental and emotional disorders. Using music as a primary treatment modality, specially trained music therapists can provide in-depth therapy in the areas of assessment and treatment planning, the treatment process, and evaluation of treatment progress. Therapists from other theoretical orientations can also utilize music therapy approaches that 
are compatible with the therapist's particular theoretical framework, skill level for implementing the intervention, and the client treatment issue.

Music is a universal human phenomenon. It originated from the imitation of nature's sounds--the songs of birds, calls of animals, and sounds of streams, lakes, oceans, wind and other naturally occurring events. Music is the result of the conscious development of sound. With the development of music came the development of musical instruments, and whether composing, playing, or listening, an individual is impacted by music. The importance of sound and music has been documented since human kind's early beginnings and its abilities to aid in the emotional healing of an individual is receiving increasing attention.

Music consists of five major components, which are pitch, intensity, timbre, interval, and rhythm. These qualities are what account for the varying impact different kinds of music has on our senses and emotional state. Music's impact also can be deeply experienced because it can be comprehended physiologically by both sides of the brain, one side dominated by analytical reasoning, the other by abstraction. Psychologically, music reaches us at id, ego and superego levels and can serve to provoke, release, or soothe. The main psychological effects of music on an individual fall into the categories of communication, 
identification, association, imagery, self-expression and self-knowledge.

It appears that music therapy approaches can address a variety of treatment issues and be used with many types of client populations. Music therapy approaches have been effectively used to do the following therapeutic work:

1. Uncover and release deep seated, unconscious emotions.

2. Bring feelings to the conscious level.

3. Establish new sense of self and ability to practice adaptive behaviors.

4. Lower client defense mechanisms.

5. Identify cycles of emotions.

6. Identify thinking patterns.

7. Use imagery to facilitate emotional growth and change.

8. Provide focus and visualization in goal setting.

9. Reduce anxiety and promote relaxation.

10. Develop problem solving skills.

11. Understand and manage unhealthy emotional triggers.

12. Provide healthy escape; encourage a sense of playfulness and joy.

13. Help build stability through repetition and consistency. 
It seems that music therapy interventions are significantly successful as part of the therapeutic experience and can impact and facilitate client change at a very deep level. A continued look and exploration into where such approaches can be used to complement a counselor's work is warranted. 
CHAPTER III

\author{
DESIGN OF THE STUDY
}

COUNSELING THE CORRECTIONS CLIENT

Criminological theories are often not so much proven wrong as simply pushed to one side in favor or newer interpretations. The hope of the social sciences, of course, is to achieve an elegant simplicity, and perhaps in time the explanation of crime will form a coherent whole. (Sykes, 1967, p. 6)

As previously mentioned, the uses and applications of music therapy are increasing. What use might music therapy have in treating the criminal population, specifically, those who are serving time in prison? To explore this possibility, an examination and evaluation of the criminal personality and related treatment issues is in order.

Numerous criminological, sociological, and psychological theories have evolved over the years to either explain the presence of crime or attempt to develop effective solutions and preventive measures toward crime in society. Several theories are discussed here that have been found to be useful in counseling the corrections client. Probably the most important issue in counseling corrections clients is to recognize that no single theory can explain all offenders, just as no single intervention or counseling theory is effective in treating every client. offenders are 
differentiated by many characteristics; in fact, the only thing they all have in common is that they have been convicted of breaking the law (Foraker-Thompson, 1992).

The intent of this author in presenting the following theories toward criminal behavior and/or counseling the criminal is to provide an overview of what is already available that can aid counselors in learning about their client and developing the most appropriate treatment plan. A knowledge of many theories can help counselors to better understand their clients and implement that understanding in their ongoing practice through meaningful interventions, which includes the use of music therapy.

Criminal Behavior Due to Criminal Thinking Errors

In the mid 1980s, Dr. Stanton E. Samenow, noted clinical psychologist specializing in criminality issues, co-authored with the late $\mathrm{Dr}$. Samuel Yochelson a landmark three-volume study of the criminal personality (Yochelson \& Samenow, 1986). The major premise put forth by Drs. Samenow and Yochelson was that criminal behavior stems from a characteristic set of thinking patterns, often referred to as criminal thinking errors. Some of the more pronounced of these thinking errors, from a list of 36 errors identified, include: (a) anger as a way of controlling people and situations; the need for power and control over others; portraying oneself as the victim in this life and 
maintaining a victim stance when held accountable for irresponsible actions; (c) belief in one's ownership of something, and justification for doing whatever one needs to get ownership of what one wants; (d) fear of fear, which leads to strong denial within the criminal any feelings of fear, doubt, concern, apprehension, or anxiety; (e) lack of trust in anyone, though the criminal demands that others trust him or her; and (f) superoptimism, where in the criminal's mind, an idea is a reality. For example, if a criminal decides to become a responsible person, he or she then believes that the change has already occurred.

Further, in counseling the corrections client, these same thinking errors manifest themselves in specific behavioral tactics that obstruct effective treatment and change in the criminal. Such tactics surface dramatically when the criminal is held accountable in a program for change, for instance, in a therapeutic treatment program while in prison (Yochelson \& Samenow, 1986).

To work toward a solution to society's escalating crime problem, Samenow's $(1984,1989)$ individual works also presented the belief that to understand and treat the criminal, one needs to realize that the criminal personality has a fundamentally different view of the world from that of people who are more or less responsible in their actions. To him, the place to start in treating the corrections 
client was to understand what criminals were really like by looking at how they think (Samenow, 1984).

The work of Bayse (1991), certified family life educator who has developed correctional treatment models in the state of Alabama prison system, reinforces this picture of the criminal population. He provides a description of the criminal mentality as a state of mind that has specific, defining features with regard to the criminal's thinking process when committing a crime. His model describes four characteristics inherent in the committing of a crime. They are as follows: (a) seeing something that you want but have no right to have; (b) declaring that nobody has the right to tell you to control your urges; (c) declaring that the rules of society do not apply to you, so you can violate them without paying the penalty; (d) abusing your power and taking it (Bayse, 1991).

Bayse's (1991) work is interesting because it takes a family approach to treatment and while responsibility and accountability rest with the criminal, interventions are implemented toward rebuilding the family structure for the corrections client/inmate as he or she changes unhealthy aspects of his or her life. A paramount goal for treatment is not just to reshape how the criminal thinks, but also to teach sound family life education in an effort to facilitate inmate change within the family structure. This allows the 
inmate to begin playing a responsible role in the family structure.

\section{Control Theory}

offering a different perspective, control theory comes from the field of sociology. It does not examine and list the conditions that may lead people to commit crimes, but looks at conditions that isolate people from it. These conditions, also known as controls, are attachment, commitment, involvement and belief. The presence or intensity of the attachment is the influencing factor on the presence of the other three conditions (Walsh, 1992).

Control theorists do not believe that criminal beliefs cause one to commit crimes, but these beliefs do provide a means for the criminal to rationalize what he or she has done. An understanding of control theory can be beneficial when counseling the corrections client. Interventions can be considered taking into account their ability to increase attachment, commitment, involvement and/or belief within the client toward someone or something else. Elements of the theory can be utilized to better understand criminal behavior and to recognize real life conditions in the client's life that can be rectified in the counseling experience (Walsh, 1992). 
Transactional Analysis

Transactional analysis (TA) is a cognitive counseling theory, formulated by Dr. Eric Berne in the early 1960s. The theory became quite prominent, in large part due to the publication of the books Games People Play by Berne (1964), and I'm Okay--You're Okay by Harris (1967). The popularity of these books resulted in a widespread attraction for the theory and use of transactional analysis (Gladding, 1988).

Transactional analysis stresses the cognitive and behavioral aspects of personality rather than the emotional. It focuses on the structural analysis of each individual (parent, adult and child states), the nature of transactions between two or more people, the games (transactions between people) played between individuals leading to bad feelings, and the life scripts an individual is following.

Understanding these four elements provides the framework for cognitive and behavioral change (Berne, 1964).

Transactional analysis has been found to be very useful in counseling corrections clients. It illustrates in a simple yet meaningful way the consequences of feelings one has about the self or about others in everyday transactions. These ideas can be relayed to clients in order for them to analyze their own feelings and behaviors. A particularly noteworthy feature of TA in relation to corrections clients is its emphasis on manipulation and game playing. In addition, TA easily describes through the parent, adult, and 
child states, how early love deprivation leads to poor selfconcept, thus leading to negative images of others and poor interpersonal relationships (Walsh, 1992). A therapeutic goal of the counselor through understanding such a dynamic might be to use this information in conjunction with creating a therapeutic environment that demands accountability and responsibility.

\section{Rational-Emotive Therapy}

Another cognitive theory used successfully with corrections clients is rational-emotive therapy (RET), founded by Albert Ellis. RET revolves around Ellis's A-B-C theory of personality: $A$ is the activating event; $B$ represents one's subjective interpretation about $A ;$ and $C$ is the consequence, or emotional content or behavior based on B. The important feature in this discussion is the understanding that $A$ is not the direct cause of $C_{i}$ it is $B$ (one's interpretation about an event), which leads to C (Ellis, 1974).

Part of RET is to uncover one's patterns of irrational thinking that leads to maladaptive behavior. These irrational thoughts share common themes with Samenow and Yochelson's criminal thinking errors and when used with corrections clients, the counselor can often be quite effective in helping the client to recognize and begin to challenge and change irrational thinking. Here the therapeutic goal is cognitive restructuring (Corey, 1986). 
Reality Therapy

Reality therapy, founded by Glasser (1965), is another popular counseling approach with corrections clients. In fact, Glasser developed the core ideas for reality therapy while working in a correctional setting. Reality therapy is a behavioral approach that expects accountability for behavior on the part of the client, believes in the dignity of the client and believes that client change is possible (Walsh, 1992).

Reality therapy is concerned about the here and now and dwells very little on client deficiencies. Reality therapists move a client toward concentrating on present self-defeating behavior, and teaching new behavior strategies (Gladding, 1988). As a theory, it also recognizes the importance of a warm, respectful and open client/counselor relationship stressing positive regard, genuineness, and empathy (Glasser, 1965).

\section{THE CRIMINAL'S SELF IMAGE}

Criminal thinking errors, values, and beliefs inherent in the criminal personality co-exist with the criminal's own self image. Samenow found in his work with males in prison that the criminal believes that he is a decent human being. This phenomenon is dramatically illustrated through the observation of a therapy group at the oregon state Hospital (Samenow, 1984). 
The therapy group was made up of dangerous sex offenders who were receiving psychiatric treatment. Among them was a man who had raped babies, a man who had sodomized a 6-year-old boy, another who had raped a 14-year-old girl at gunpoint, and 10 others with a combination of every imaginable kind of sex offense, in addition to other types of crimes. The therapist asked the group why society has rules and received answers such as "We have rules to protect society and so people won't hurt others," or "Rules are designed to teach people their responsibilities." All answers from the clients were rational and to the point, and they were being articulated by people who had committed some horrendous crimes. These same men knew that the crimes they committed were wrong and knew why they were wrong. They could even acknowledge that, from society's point of view, they were considered criminals. However, not one member of the group really regarded himself in that way (Samenow, $1984)$.

The criminal knows right from wrong; is probably more knowledgeable than most responsible citizens about the law. When it suits him, he is law-abiding and can even take pride in this. Despite his knowledge of what is right and wrong, legal and illegal, the criminal makes exceptions for himself just because it suits him at a particular time. The fact that he wants to do it makes it right in his mind (Samenow, 1984). 
If a criminal regards something to be personally wrong for him, he will not do it. For instance, if an act is too risky, it therefore is wrong; if an act is thought to be too petty, it is then considered wrong. A very interesting feature related to this is the criminal's assessment of something being wrong in relation to getting caught for the crime. In other words, a criminal may make an error in judgment and get caught. He views his action as wrong, but it is because he got caught, not because he did the act itself (Lester, 1981).

As already mentioned, the criminal knows right from wrong, but paradoxically he also believes that wrongdoers must be apprehended. Criminals do not necessarily hate the police; in fact, many criminals have a fascination for the police that extends into their adult years. Often the criminal is a fervent viewer of police shows and detective thrillers (Samenow, 1984).

The criminal operates according to his own set of morals. If there is something he wants, he does whatever he needs to do to get it. Though criminals can experience guilt and remorse, their conscience is not completely operational. After committing a crime, considerations of conscience can be shut off quickly and completely. In fact, one of the roles that guilt can play for the criminal is the belief that because he is capable of feeling guilt, it reinforces the belief that he is decent (Bayse, 1991). 
The criminal thinks very highly of himself, tends to be idealistic, and is often remarkably talented. Prison art shows have displayed beautiful works of gifted painters who have had little or no formal training. Some criminals are musically gifted and can perform their own compositions on instruments that they learned to play totally by ear. Many others do not play music, but have extensive interests in music and its power to affect emotions. An inmate serving time at a federal penitentiary who had a passion for Bach declared that, "To me, music is everything" (cited in Samenow, 1984, p. 157).

other criminals are excellent craftsmen, or have a brilliant knack for dismantling and repairing a wide variety of things. The creative potential within the criminal population is vast, but the criminal lacks the discipline to develop these talents. He has little interest in training or apprenticeship programs, which entail drudgery and a strong degree of perseverance. Rather, the criminal expects to complete a polished product or masterpiece overnight. When he discovers that this is not possible, his interest fades (Samenow, 1984).

These conditions of failed potential or the setting of unrealistic standards are also apparent in people who are not criminals. What impedes the criminal's ability more than anything else to realize his talent and potential is the belief that the process of doing so is completely 
meaningless. The criminal finds no meaning in the process of achievement, unlike the responsible person (Samenow, 1984 ).

\section{THE CRIMINAL AND DRUG USE}

Hand in hand with criminal thinking errors are the use of defense mechanisms in the form of thinking errors that are characteristic of the chemically dependent individual. These include minimizing, manipulation, victim stance, power plays, blaming, superoptimism, and need for drama and excitement. It is true that not all drug abusers engage in criminal activity, but most people who engage in criminal activity abuse drugs (Ragghianti \& Glenn, 1991).

The assertion of Yochelson and Samenow (1986) in Volume III of their series on the criminal personality, The Criminal Personality, Volume III: The Drug User, is that though a criminal's drug use can pose special problems, in fact, an individual's criminal activity is firmly entrenched before the use of drugs in his or her life. The reasons for drug use may be of value in developing a treatment plan, but criminality and criminal thinking errors remain at the core of the criminal's behavior.

In examining further the thinking errors of the drug using criminal, some significant findings emerge. One is that although drugs per se did not make someone become a criminal, they do facilitate criminal thinking. Drugs allow 
a criminal to elaborate his or her fantasies and they increase the amount and speed of one's thinking about crime and exploitative sex. For a criminal drug user, achieving that drug high is to feel all powerful. This desired feeling is true of all criminals, but some are able to experience it without the use of drugs (Yochelson \& Samenow, 1986).

\section{TREATMENT ISSUES}

To help criminals change, the therapist must work with such a client to help him or her alter his self-concept and view of the world. Some criminals do want to change; this is the target population for the therapist; part of that habilitation is helping the client acquire patterns of thinking that are completely foreign to them but essential if they are to find success in living responsibly (Bayse, 1991; Samenow, 1984; Walsh, 1992). Paramount in the treatment of the criminal personality is the importance of expecting accountability and responsibility and utilizing treatment interventions that reinforce these expectations.

In adopting such an approach, the therapist's task, for one, is to become thoroughly familiar with how the criminal thinks. Another is for the counselor to consider other key issues surrounding the criminal environment such as level of attachment with significant others, evidence of early love deprivation or other significant early childhood 
developmental milestones, and a review of prominent criminological and sociological theories. A therapist with this frame of reference is then in a better position to formulate policies, administer programs, create realistic treatment plans, render more informed decisions, and be more effective in direct contacts with criminals whether that direct service is in institutions or in the community (Walsh, 1992).

A critical piece in successful counseling with the corrections clients is that the client has to make the choice to change; then, the counselor must insist that the client be treated as responsible and held accountable for his or her behavior. It also involves facilitating a change in the client's belief system that one's emotions arise from outside oneself and that one has no real control over the emotions or resulting behaviors. statements reflecting the belief system of criminality include such things as a client saying he cannot control his anger, or that he smoked dope because he was bored and feeling depressed (Berne, 1964; Samenow, 1984; Walsh, 1992).

The corrections client who does have access to and is participating in therapeutic treatment typically is involved in treatment that is multidisciplinary in approach. That is, the therapist typically employs techniques from a variety of sources, in particular including elements from transactional analysis, rational-emotive therapy, reality 
therapy, behavior modification, Twelve Step concepts, and meditation (Ragghianti \& Glenn, 1991).

with incarcerated clients, the emphasis is usually on having inmates assume personal responsibility for their actions (Ragghianti \& Glenn, 1991). A typical treatment plan includes the following: (a) basic information and education on criminality and/or chemical dependency; (b) group and individual counseling; (c) lectures on recovery principles; (d) peer group interactions; (e) use of audiovisual aids such as films and/or videotapes (Ragghianti \& Glenn, 1991).

It is important that the corrections client develop a more realistic view of one's self and the world, thereby developing a more tolerant stance toward life and life events. The next step for the client is to then learn to react more constructively when things do go wrong, to learn to anticipate difficult or stressful situations and think them through in advance. To do this is to help gain not only a pro-social behavior to develop a personal stability for life outside prison (Samenow, 1984).

From information gathered from the therapeutic programs operating within oregon's prison system and from literature regarding the counseling of corrections clients from other parts of the United States, prominent issues appear that need to be addressed in working with the corrections client. 
Though each treatment issue is not applicable to every client, the major treatment issues include the following:

1. Self-Development Issues

- Development of individual responsibility for one's behavior

- Identity, awareness, and ownership of one's thinking patterns

- Identity, awareness, and ownership of one's own feelings

- Development of effective communication skills Grief/Loss

Trust/Relationships/Abandonment

Developing healthy boundaries

2. Self Control Issues

- Anger Management/Developing tolerance for

frustration

- Stress Management

- Relaxation/Leisure Skill Building

- Power/Control/Manipulation

- Isolation/Avoidance

- Impulsivity

3. Coping Skills

- Adjustment/Change (including transition back to society)

- Developing realistic goals

- Developing support networks 
- Developing family, parenting skills

\section{CONSIDERATIONS FOR COUNSELORS}

\section{Treatment setting and}

\section{Philosophy}

In addition to possessing a knowledge of the criminal personality and understanding the basic theories of counseling, it is recommended that counselors understand the philosophy and dynamics of their particular treatment setting, as it influences the types of interventions utilized and impacts one's ability to introduce new approaches. For example, a review of the oregon prison system shows the existence of several mental health treatment programs. Although providing therapy is a primary service with each program, there are also differences between them that significantly influence the type of treatment and methods employed. One aspect to consider is the particular type of corrections client being served and the severity of the client's conviction. Separate programs currently operate for sex offenders, voluntary mental health clients, involuntary mental health clients, and substance abuse clients. Additional considerations within each of these programs include whether or not the program is mixed gender, whether or not clients are mandated or voluntary, or whether or not the treatment aspect of the program is maintained on a 24-hour basis. 
This last issue highlights prison programming's impact on counselors. The Oregon State Penitentiary's Mental Health Treatment Unit (MHTU) in Salem maintains a 24-hour treatment staff, though the bulk of direct treatment occurs between 8:00 a.m. to 5:00 p.m. daily. No corrections officers are present on the unit in order to maintain the therapeutic environment at all times. Other programs, such as Turning Point at Columbia River Correctional Institution in Portland, provide treatment services during the day with corrections officers coming on duty during the night shift, creating different issues regarding treatment that staff must address. 1

other aspects about the treatment setting relevant for the counselor are the treatment approach philosophy (e.g. eclectic or behavior modification focused), extent of educational programming available for client in the areas of criminality, mental illness, substance abuse and other important topics, accommodation for group and individual counseling, philosophy and program operation around the use of medications, and the location of clients in treatment in relation to other inmates who are part of the general prison population.

1 This information was gathered from phone interviews, personal contacts, and this author's knowledge and experience from eight years professional involvement with corrections agencies. 
Group and Individual Process

The foundations that create an effective therapeutic relationship apply to both individual and group therapy in the use of music interventions. These include: (a) establishing therapeutically beneficial ground rules for client sessions; (b) providing a safe and comfortable environment; (c) modeling appropriate behavior; (d) using interventions appropriate to client issues; and (e) awareness of client's stage of therapeutic development (Corey, Corey, Callanan, \& Russell, 1988).

In using music therapy within a group setting, competence in creating group unity should be highly developed, with the additional ability to meet individual client needs. An understanding of group dynamics is very important; indeed, with the use of musical interventions, there are benefits that can sometimes only be derived in the group setting. When a group makes music together, a unique experience of energy, group unity and connectedness can take place. In addition, through this group activity, the therapist creates and nurtures connections between clients, both verbally and nonverbally (Boxill, 1987). The music therapy group can be viewed as a microcosm of the client's social world, and it is in this world where self and interpersonal relationships can be explored and changed. Seen in this perspective, the music therapy group can function in the same way as traditional verbal groups, with 
opportunities for reality testing, support and sharing, peer identification, modeling, leading and following (Bruscia, 1987).

Finally, special consideration must be paid to the therapist's level of musical knowledge and/or comfort and clients' musical comfort level. As noted earlier, many criminals are highly creative or musically talented, and performing can be of particular pleasure. The purpose of musical interventions should be congruent with the treatment goals; however, it is critical that clients not be involved in musical experiences where they are made to feel as if performance is the goal, or that musical aptitude is necessary. Such an atmosphere does not promote therapeutic growth (Boxill, 1987).

In individual counseling using music therapy, the musical interaction is much more intensive and can place additional demands on the therapist. On the other hand, this environment may be more comfortable for the client to musically express his or her issues in a more spontaneous manner (Boxill, 1987).

\section{EVALUATION AND SUMMARY}

Numerous theories offer varying and sometimes conflicting perspectives about the causes of and treatment for criminal behavior. These theories originate from many fields, including criminology and criminal justice, 
sociology, psychology, social work and counseling. The preceding review of such perspectives has uncovered information that points to some distinct characteristics regarding self-concept and world view that is evident in the criminal personality. Such a perspective is better understood by examining thinking patterns of an individual that lead to and perpetuate criminal behavior. An understanding of these thinking patterns, values, belief systems and environmental conditions surrounding the corrections client is extremely useful for the counselor working with the corrections population, for they not only determine how a criminal behaves but also influence his or her behavior and use of defense mechanisms as a resistance to treatment. Some effective treatment interventions for the corrections client include transactional analysis, rational-emotive therapy, reality therapy, as well as an eclectic approach that combines elements of these theories and others.

Knowledge of a criminal's thinking errors, self image, and drug use history provides comprehensive material for the counselor to develop an appropriate treatment plan and prioritize treatment issues. Pronounced issues for the corrections client can be classified in three major areas: (a) Self development issues, which include examination into criminality as well as cognitive, emotional, and behavioral traits; (b) Self control issues, which address the client 
characteristics of power and manipulation, impulsivity, anger and stress, and others; and (c) coping skills, which include development of goals, support networks, and healthy relationships. Issues within each of these areas have been identified and corroborated by several professionals in the field of corrections and mental health as critical to facilitating client change, with the goal to: (a) reduce the percentage of individuals who return to a criminal lifestyle and ultimately, prison; and (b) assist corrections clients to develop new, adaptive behaviors that allow for living successfully within society and outside the prison walls.

Paramount in the treatment of corrections clients is creation of a treatment program that demands accountability and responsibility from each client. Criminal thinking errors and deep emotional levels need to be identified, uncovered, processed in a therapeutic environment, and challenged so the client can develop and embrace new belief systems, a new self-concept, and an adapted world view. In treating corrections clients, attention must be paid to the differing or additional needs of female inmates, and sensitivity and consideration given to cultural issues of clients within the larger context of criminality issues. This can be accomplished by using a holistic, individualized approach in assessing, treating and evaluating clients and client needs. 
CHAPTER IV

RESULTS

MUSIC THERAPY MODEL FOR CORRECTIONS CLIENTS

IN THE PRISON SETTING

The following is a proposed model for utilizing music therapy as an intervention with corrections clients in the prison setting. It is designed for use in conjunction with other therapeutic approaches that address a corrections client's treatment issues. It is an approach that can be integrated into already existing settings and utilized in many ways and for many issues if a therapist chooses to employ the use of music as an additional way to facilitate client growth and behavior change.

\section{SALIENT FEATURES}

The preceding literature review has provided information about how music therapy can be effectively used in a therapeutic manner and about the types of issues commonly facing the corrections client with whom the counselor would be working. Issues relevant to both areas that offer direction to the therapist when choosing music therapy as an intervention tool include the following: 
Assumptions About Music

Therapy and the corrections

client Population

1. Music therapy can be effective in helping to uncover deep seated, unconscious emotions. A common treatment issue for corrections clients is the need to learn to gain awareness and ownership of one's thoughts, feelings, and emotions.

2. Music therapy can help a client in establishing a new sense of self and practicing corresponding, adaptive behaviors. This is a critical area of treatment for the corrections client, as well.

3. Music therapy interventions can reduce client anxiety and promote relaxation. Relaxation and stress management are key skill building areas recommended for corrections clients.

4. Music therapy can aid in the development of problem solving skills. Prior to treatment, corrections clients' skills in decision making and problem solving are limited and often maladaptive. Problem solving becomes even more important as the client transitions from prison and is expected to succeed in the outside world.

5. The use of music therapy can promote client understanding and management of unhealthy emotional triggers. For the corrections client, past behavior has been characterized by impulsivity and by the need to control and manipulate; again, this is a key area for treatment in 
helping facilitate change toward accountability and responsibility.

Assumptions About Counselor Use of Music Therapy Approaches

This proposed model provides a structure that the counselor would follow as part of a treatment plan within the prison setting. Within this process, decisions are made about client treatment issues and appropriate interventions, of which music therapy can be a part. The treatment plan is comprised of treatment issues and interventions related to the following eight areas: (a) legal/criminality; (b) abuse/addiction; (c) physical and mental health/medical; (d) psychological, emotional, spiritual; (e) family/support network; (f) social/interpersonal relationships; (g) educational/occupational/financial; and (h) recreation. ${ }^{2}$

A sample of specific music therapy approaches is offered that works toward treatment goals in each of these areas. The approaches are ones that have been found to be useful therapeutically, and which seem to be appropriate for the corrections population.

2 Development of music therapy model and problem areas selected for treatment planning was the culmination of interviews and information gathered from treatment and corrections programs, and greatly enhanced by the author's counseling internship experience at Turning Point Drug and Alcohol Treatment Services, a division of ASAP Treatment Services located at Columbia River correctional Institution. 
Another important feature of this model is that the interventions are able to be used by therapists who specialize in theoretical approaches other than music. They do not require the qualifications of a registered music therapist, nor does the therapist have to be a professionally trained musician to successfully employ these approaches. This model uses music therapeutically, but it does not exist within a framework where music is considered the primary treatment modality, nor does it contain the more complex music therapy interventions that necessitate a high level of training in music and music therapy. Instead, music is the basis for several possible interventions that can enhance the work already being done with corrections clients and when incorporated, enhance the therapeutic experience. It includes a selection of music therapy interventions that can be effectively utilized by the therapist. Interventions described in this model can be appropriate in individual and group counseling sessions. Again, the decision about where and when to use such an intervention is made using the same criteria that the therapist would use to make a decision about any other type of intervention.

\section{STRUCTURE OF PROPOSED MODEL}

Music therapy interventions can be implemented through integration into the larger therapeutic structure. Toward 
the use of music therapy with the corrections client, it is recommended that the counselor proceed with the following five step process, which this author believes is compatible with most therapeutic structures within the prison system (see Figure 1):

1. Intake/Assessment: This would include a client interview, completion of a psychosocial evaluation and evaluation of other information previously provided by the client to corrections officials. For purposes of potential music therapy interventions, a question about a client's interests, opinions, or experiences with music or song could be included, most likely as part of assessment inquiries about leisure or personal activities.

2. Development of Treatment Plan: This is developed from the results of the psychosocial evaluation and through initial sessions between the client and therapist(s). As noted earlier, the recommended treatment plan for the corrections client would contain issues that fall into the following categories: (a) legal/criminality; (b) abuse/addiction; (c) physical \& mental health/medical; (d) psychological, emotional, spiritual; (e) family/support network; (f) social/interpersonal relationships; educational/occupational/financial; and (h) recreation. 


\section{Proposed Model for Music Therapy Integration}

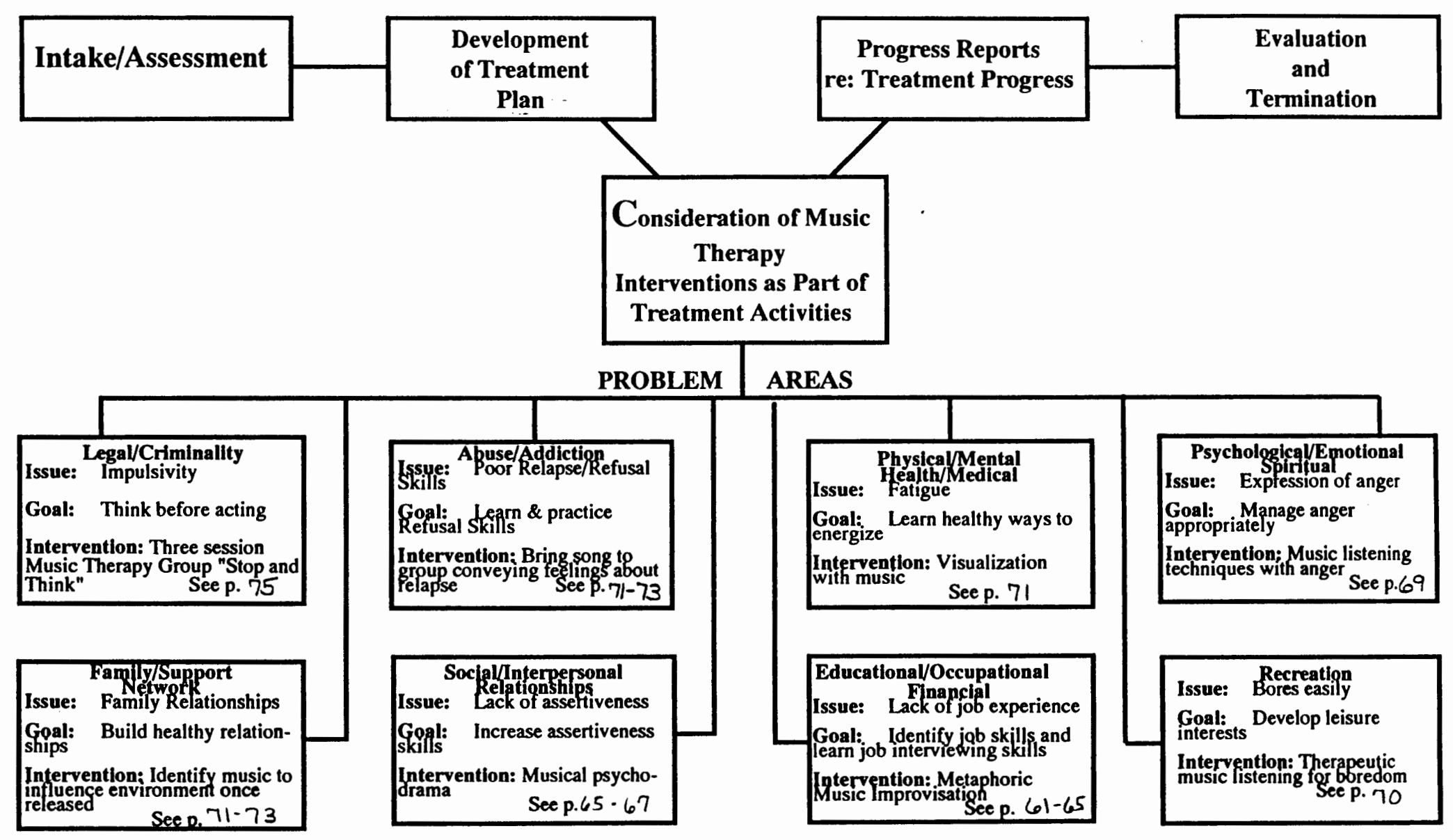

Figure 1. Proposed model for music therapy integration. 
For each identified problem area, the plan should also list one or more treatment goals as well as possible treatment activities that could help achieve these goals. Here is where music therapy approaches could also be listed and incorporated into the treatment plan (see Figure 1).

3. Consideration of Music Therapy Interventions:

Interviews at prison treatment programs show the use of various interventions based on factors already outlined in this thesis such as type of client being served, skill area and philosophy of the treatment program and staff, and length of treatment. Interventions currently being listed under treatment activities are ones now being used in the treatment setting, originating from either the treatment organization or incoming staff. Materials (when applicable) and counselor training for specific activities are available.

It is recommended that music therapy interventions be established in writing for the various problem areas and/or treatment issues. Such interventions could then be listed and considered by the counselor under treatment activities. This would be particularly important when the staff person doing the assessment is different from the counselor who is providing the primary therapy services to the client. It would be especially helpful to create and have available a curriculum for music therapy interventions specifically related to common issues counselors encounter when working 
with corrections clients. To provide an appropriate introduction and overview of music therapy interventions for use by all staff, it is recommended that some kind of inservice training be provided.

4. Progress Reports: It is recommended that regular progress reports be kept on each client in addition to case notes. Counselors would use the progress report to monitor client therapeutic activity from week to week, as well as outline types of interventions being utilized. The notes kept here regarding music therapy could be very helpful for future use of music therapy, as it is less explored and documented than other, more established interventions.

5. Evaluation: It is important to provide some means for evaluating client treatment. The method to accomplish this should be a combination of counselor evaluation of client progress toward treatment goals and interventions found to be effective through observation of the client while in the prison setting, and through feedback from the client, either through an exit interview or through client completion of an evaluation form regarding treatment. A specific form focusing only on music therapy interventions could also be considered.

\section{PROPOSED MUSIC THERAPY APPROACHES}

Contained within the proposed model are eight specific music therapy interventions offered for each of the eight 
problem listed. The following section describes the music therapy approaches offered as part of the model. It is this author's hope that a description of these approaches will provide an example of some of the different ways in which music can effectively enhance counseling services to corrections clients.

The main types of music therapy approaches, of which there are thousands, fall into six major categories. These are improvising, performing, composing, notating, verbalizing, and listening to music (Bruscia, 1987). This proposed model consists of interventions from the areas of improvising, listening to and composing music (including the use of voice and/or lyrics). These three approaches seem most appropriate to the client setting, can address the client issues, and be effectively implemented by counselors.

Interventions described in this model can be appropriate in individual and group counseling sessions. Again, the decision about where and when to use such an intervention is made using the same criteria that the therapist would use to make a decision about any other type of intervention.

\section{Improvisational Approaches}

Improvisational music therapy consists of interventions where the musical experience is accomplished through the playing of musical instruments. The process is spontaneous in nature and the results are not necessarily "music"; it 
may be more in the form of sound forms that reflect the emotions or atmosphere of the session (Bruscia, 1987). Improvisational music therapy can address many goal areas; some that apply to the corrections population are as follows :

1. Awareness of physical, emotional, intellectual, or social self.

2. Awareness of physical environment.

3. Insight about self, others, and the environment.

4. Self-expression.

5. Interpersonal communication and relationship building.

6. Integration of self.

Three particular improvisational approaches are described in this thesis that could be utilized by counselors who work with corrections clients. They are free improvisation therapy, metaphoric improvisation therapy, and musical psychodrama. Two of these forms, metaphoric improvisation therapy and musical psychodrama, have been highlighted in Figure 1, as interventions to the client problem areas of lack of job experience and lack of assertiveness, respectively. They are each discussed here.

Metaphoric improvisation therapy. This model combines music therapy with psychotherapy and was developed in the 1960s by Shelley Katsh and Carol Merle-Fishman (cited in Bruscia, 1987). It was developed for use with adults with 
neurotic or psychiatric disorders, and for well-adjusted adults wanting to further develop their personality or resolve specific life problems. Originally conceived as individual therapy within a group setting using two therapists, it has since been adapted by other therapists and used effectively for individual, group, or couples therapy with the use of one or two therapists. The foundation of metaphoric improvisation combines elements from Gestalt therapy, Transactional Analysis and developmental theory.

During the course of treatment, the counselor seeks to facilitate within the client an awareness and focus on feelings, in keeping with its underlying foundations of gestalt and transactional analysis features (Bruscia, 1987).

The two major features of this intervention are improvisation and verbal discussion. The use of improvisation on the part of the therapist is termed clinical improvisation and is defined as "the use of spontaneous composition to accept, support, and provide new direction for a person's musical and emotional experience in the here and now" (Bruscia, 1987, p. 319). And in the overall approach, the main consideration with metaphoric improvisation is to address the here-and-now needs of the client.

To do this, sessions may take any format and be structured by either the therapist or client, depending on 
the needs of the moment. Verbal discussions are held before and/or after the improvisations, usually focusing on how the client's musical experience relates to personal, real life experiences. The music, then, is seen as a metaphor for the client's emotional and social life and the metaphors become the center for discussion. Musical skills or abilities are of no importance to the client's ability to fully participate in this intervention.

Metaphoric improvisation therapy is made up of five working phases: warm-up, identifying a client issue, experimentation, consolidation, and closing. Every session begins with a warm-up and a close, and the middle of the session consists of the repetition of the middle three phases of the cycle until the therapist has worked with every client and/or when all of the most pressing issues have been addressed (Bruscia, 1987).

If used in a group setting, the warm-up serves as the time when group members introduce themselves, the counselor explains the dynamics of the approach, and then asks clients to select an area of their life or a problem they would like to work on during the session. Through discussion, a flexible contract is established with each client that specifies the client's goal and what the client is willing to do to accomplish this goal within the context of the therapy session. The counselor or counselors should use this contract creation as an opportunity to establish 
rapport and build trust with clients. If the group has met previously, the purpose of the warm-up is to reorient the group to a therapeutic environment and establish work objectives for the session, or to review or revise contracts (Bruscia, 1987).

In the issue identification stage, the three phase cycle begins and is repeated and completed with each client individually. The issue identified during the warm-up is often just a clue to what the more significant issue may be. Music and sound are now utilized to reach identification of the issue. To help facilitate this, the therapist can employ several techniques musically, such as guided fantasy, relaxed listening, and free improvisation. With guided fantasy, the client is asked to imagine sounds associated with a particular situation, which can be demonstrated to the group or described verbally. Relaxed listening uses two therapists; one provides musical improvisation to help the client relax, while the other therapist verbally induces a relaxation state by giving suggestions for each body part. clients are instructed to let their bodies respond to the improvised sounds and begin to make connections between their body and the sounds. In free improvisation, a choice of percussive, melodic, and harmonic instruments is offered and clients and asked to improvise freely. Clients are also asked to observe their own musical actions and reactions and 
pay attention to sounds they like and dislike (Bruscia, 1987).

The experimentation phase is when clients act out their issue through music and the creation of musical metaphors. Forming such a metaphor is the work of the client, though the therapist may offer suggestions when necessary. The objective here is that the metaphor belongs to the client and its meaning is recognized and accepted as relevant to the issue. The sources for musical metaphors most often come from sound associations from the previous work phase, awareness of one's self and others in the music making process, or associations developed through the discussion of the client's issue. One effective way to elicit the metaphor is to ask the client how a certain aspect of the issue would "sound." Sometimes the issue has an accompanying sound; other times it may not be the sound that is significant but some other element, such as timing between sounds, or quickness of playing. Sometimes, too, the attraction to a particular instrument is the basis of the metaphor and the client issue. Many different improvisations and discussions can take place in this phase (Bruscia, 1987) .

During consolidation, the therapist and client engage in discussion around what the client experienced while working through an issue and what might be gained through this musical process. Particular attention is paid to 
helping the client link the metaphoric experience to real life problems, issues, or life experience. One notable feature of the consolidation phase is that, when done in a group setting, the witnessing of another's working through an issue creates identity and connectedness between clients. The discoveries of one client often raise or further define issues for other clients, providing a thematic unity for the session (Bruscia, 1987).

closure is accomplished when all clients have participated and the resulting experiences have been reviewed and integrated. closure is reached through musical and verbal means; musical closure may be through free improvisation or performance and verbal closure generally involves summarization of experience and of the session and its process (Bruscia, 1987).

Musical psychodrama. Musical psychodrama, developed in the late 1970s by Joseph J. Moreno, blends elements of psychodrama and music therapy to facilitate exploration of the full range of a client's emotional expression. It is an action oriented treatment approach that emphasizes spontaneity and creativity and encourages nonverbal exploration of feelings to stimulate verbal expression and insight. It emphasizes feelings in the here-and-now and discourages excessive intellectualization and verbalization. The goals of therapy through this approach are to explore and release feelings, to develop spontaneity and creativity 
in interacting with others and in facing conflict, and to acquire more adaptive behavior patterns. A therapist using this intervention should have competency in the use of psychodrama and a basic awareness of music and musical style (Moreno, 1980).

Procedures for treatment session involve the facilitation of one or two therapists. For group members, the main character is the protagonist, who is supported by other members of the group in various roles, with the remaining group members serving as the audience. The ideal group size is from 6 to 8 participants. It should be noted that this approach is also adaptable for individual therapy, in which case the therapist would take symbolic roles in the client's life as the client and therapist musically improvise a dramatic scene in the client's life (Bruscia, 1987) •

Musical psychodrama consists of the following steps: (a) verbal and musical warm-up; (b) selection of a protagonist; (c) enacting the psychodrama; and (d) sharing. The verbal warm-up involves the therapist preparing the group through group discussion with the purpose of creating an atmosphere of spontaneous, open and direct communication among all participants. This should ultimately facilitate the identification of a potential protagonist. The musical warm-up prepares clients to improvise and interpret music. one technique for such a warm-up is to ask each client to 
select an instrument and then improvise musically how it feels to be at his or her particular stage in life. These improvisations are taped, and then played back to the group for process and discussion. Another technique is for the therapist to create a guided imagery by improvising music while the group listens in a relaxed state. The therapist adapts the improvisation to reflect the group's changing emotions as interpreted through nonverbal cues (Bruscia, 1987)

The protagonist is then selected, either through voluntary means or with the assistance of the therapist. The protagonist is helped by the therapist to create a scene that depicts his or her feeling or conflict to be explored, selects other group members to fill roles involved in the scene and instructs them as to the nature of their roles (Bruscia, 1987).

The scene is then acted out along with musical assistance. The musical techniques can vary. One approach is for the actors to play out the scene musically, rather than verbally, which is known as musical dialoguing. This can be very effective when the protagonist is avoiding central issues by over intellectualization or verbalizing. Another approach is doubling, where another participant acts with or on behalf of the protagonist and musically or verbally improvises when the protagonist does not do so. 
Here, the music can complement, intensify and reinforce the dramatic action (Bruscia, 1987).

Upon completion of the scene, the protagonist is given an opportunity to reflect on the experience and the group shares its reactions and gives feedback and support. As part of closure, the therapist generally summarizes for the group a central theme or continuity of messages elicited by the session (Moreno, 1980).

\section{Listening to Music}

Some pieces of music are so powerful that they energize and inspire you at all levels of your being; other types of musical works exist that can appeal specifically to certain areas in an individual, be it physiological, emotional, spiritual, or centered on achievement of a particular altered state such as relaxation or reflection (Lingerman, 1983). As described earlier, different pieces of music stimulate different areas. In general, the following types of instruments affect the following parts of the human self:

1. Physical Body: Brass, percussion, heavy sounds from bass notes, and most electronic music.

2. Emotional: Woodwind and string instruments.

3. Mental: String instruments.

4. Soul: Harp and organ, wind chimes, high strings (Lingerman, 1983).

Utilizing music listening as a therapeutic intervention can relate to all three areas identified in counseling the 
corrections client. Therapeutic goals with this approach include the following: (a) increase physical vitality, relieve fatigue and inertia; (b) pierce through moods; (c) calm anxiety; (d) release courage and facilitate followthrough; (e) deepen relationships and connectedness with others; (f) strengthen character and constructive behavior; (g) expend levels of spirituality (Lingerman, 1983).

The following procedural guidelines are designed to assist the counselor when using this type of intervention for individual or group therapy. The therapist or clients select specific music based on the goal of the session or issues to be addressed. Before beginning the music, the therapist allows the client(s) to come to quiet. Some initial instructions might include direction to participants to speak to their bodies to relax, speak to their feelings to be calm and open, and speak to the mind to be still. Some guided imagery might be helpful in facilitating this (Lingerman, 1983).

Musical exercises should be kept short and simple, and time should be allowed after for group process and discussion as part of the session. Enough time should be allowed for the music, however, to enable the clients to absorb the music. This absorption should continue for a few minutes after the music is completed in the form of silence. It sometimes is appropriate to include the musical 
experience with another activity, such as sketching, journaling, or moving (Lingerman, 1983).

Selections from classical music seem particularly well suited to evoke particular frames of mind or address specific issues. In his book the Healing Energies of Music, Hal Lingerman (1983) developed a list of several particular musical selections recommended to address certain emotional states. Emotional states or issues pertinent to corrections clients where this type of music therapy intervention could be used include the following: (a) strong music to air out anger; (b) quiet music to calm anger; (c) music for hyperactivity; (d) music for depression and fear; (e) music to relieve boredom; (f) music for relaxation and reverie; (g) music for clear thinking; and (h) music for guided imagery and creative visualization.

The proposed model has highlighted two music therapy interventions from the listening to music category, as noted in Figure 1. Specifically, they are listening to music (under therapeutic supervision) to help with anger management, and listening to music to confront boredom, from the problem area of recreation. Some selections are as follows:

Strong music to air out anger. Selections here include the works of Beethoven (Egmont Overture); Tchaikovsky (Symphony No. 5, last movement); Saint Saens (Symphony No. 3, last movement); Rheinberger (Organ Concertos); Janacek 
(Sinfonietta); Wagner (Ride of the Valkyries Prelude to Lohengrin, Act 3); Poulenc (Concerto for Organ, Pimpani and Strings); Ginastera (Estancia); Brahms (Piano Concerto No. 1) (cited in Lingerman, 1983). These selections are cited as ones good for receiving and absorbing angry feelings because they are also powerful and large enough to provide containment along with such release.

Quiet music to calm anger. Some selections in this realm include J.S. Bach (Two Concertos for Two Pianos); Handel (Harp Concerto); Roth (You Are the Ocean); HalpernKelly (Ancient Echoes); Schubert (Prelude to Rosamunde); Dowlan (Lute Music); Gluck (Dance of the Blessed Spirits); Dexter (Golden Voyage I); and Van Eyck (Music for Recorder) (Lingerman, 1983).

Music to relieve boredom. Music in this context can serve to be a stimulus to learn and grow emotionally. Selections here include Liszt (Hungarian Rhapsodies); F.J. Haydn (Trumpet Concerto); Rimsky-Korsakov (Scheherazade); and Rodrigo (Concierto Aranquez, Fantasy for a Courtier) (Lingerman, 1983).

\section{Listening to New Age Music}

New Age music began to take form in the early 1970 s and is based on the idea that music can be created to alter moods and expand our levels of awareness. It is associated with a holistic health perspective and its musical roots are in cosmic rock music, Indian ragas, meditative folk music 
and some forms of contemporary jazz. One dimension of New Age music frequently used by healers and therapists is to use music to evoke or enhance visual imagery. This imagery becomes a powerful vehicle for self-transformation and allows the client to pass through a state of conflict and tension into a holistic state of well-being. In his book Healing Music, Watson (1987) has developed a list and description of New Age albums of music that are useful for creative visualization work with clients.

A musical intervention addressing the client area of physical/mental health has been cited in this proposed model, as shown in Figure 1. In this case, the suggested activity is for the client to use visualization to help learn health ways to energize oneself.

Music for guided imagery, creative visualization. The use of guided imagery and visualization has been shown to be a powerful therapeutic intervention and is one that can be further enhanced through the use of music (Alvin, 1966). A list of pictorial music includes Beethoven (Symphony No. 6, Pastorale); Debussy (The Sea Nocturnes, The Engulfed Cathedral); Mendelssohn (Symphony No. 3, Scotch); stravinsky (The Firebird); Vaughan Williams (Lark Ascending, Antarctic Symphony); J. Strauss (BIue Danube Waltz); Tchaikovsky (Romeo and Juliet overture) (Lingerman, 1983).

This list provides a sampling of specific types of music that can be used in the therapeutic setting and'could 
be expended upon by therapist and clients. Although a client may independently use this music later as a tool to duplicate new, more adaptive emotional and behavioral patterns, it is recommended that in the therapeutic experience with the counselor, these selections and others be used as the basis for in-depth therapeutic work. Several books are available as resources for the therapist that outline musical selections and methods for use in emotional exploration and healing.

Therapeutic Listening to

Popular Music

Listening to popular music can also be employed as a therapeutic intervention. Examples of this would most often involve contemporary modern music or music popular with the client, which might include rock and roll, blues, or alternative rock music. It is music that most often is accompanied by lyrics. In this setting, three different techniques for therapy are offered here. First, the therapist might ask a client to bring a record to the counseling session that describes their feelings at present. This is usually met with much enthusiasm, and by listening to and/or reciting the lyrics to the counselor, clients may be able to get in closer touch with their feelings (Mazza, 1981). In the prison setting, the therapist may have to bring the recording to the session, as the client most likely will not have access to such materials. 
A second technique is for the therapist to bring in music relevant to the perceived state of the client. The therapist then plays the music to express to the client how the client is being seen, or to relate to the client what the therapist thinks may be going on in the counseling session. It is critical with this technique that the client be given an adequate amount of time to agree, disagree, and elaborate on the record chosen and provide feedback. This often leads to a session consisting of rich, emotional work on the part of the client (Mazza, 1981).

A third technique is to invite the client to either make up or sing songs he or she has heard that express an important emotional client issue. The therapist then asks the client to examine the song or songs chosen and facilitate elaboration of the personal meaning or symbolism behind the song. This technique usually brings out many feelings that can be jointly explored (Ellis \& Harper, 1975) •

Any of the above techniques could be explored by the counselor when addressing the treatment activity from Figure 1, regarding poor relapse/refusal skills where a client would select and bring to group therapy some kind of song that conveys his or her feelings about relapse.

\section{Composing Music and Lyrics}

Individuals in prison often have a wealth of creativity and respond well to the prospect of creating music and 
lyrics to express their feelings or share their story. In a group setting, this can provide for a normalizing and universalization of feelings as well as serve as a springboard for discussion (Mazza, 1981). This intervention can be approached as an individual, personal activity that is shared with the counselor, utilized in a group setting where clients individually compose and then share, or intended to serve as a collaborative activity for the group that may even culminate in some kind of performance that serves a therapeutic purpose. The following lyrics were written by a group in therapy that addressed the group's termination, a significant event with such a group where client issues included abandonment and letting go.

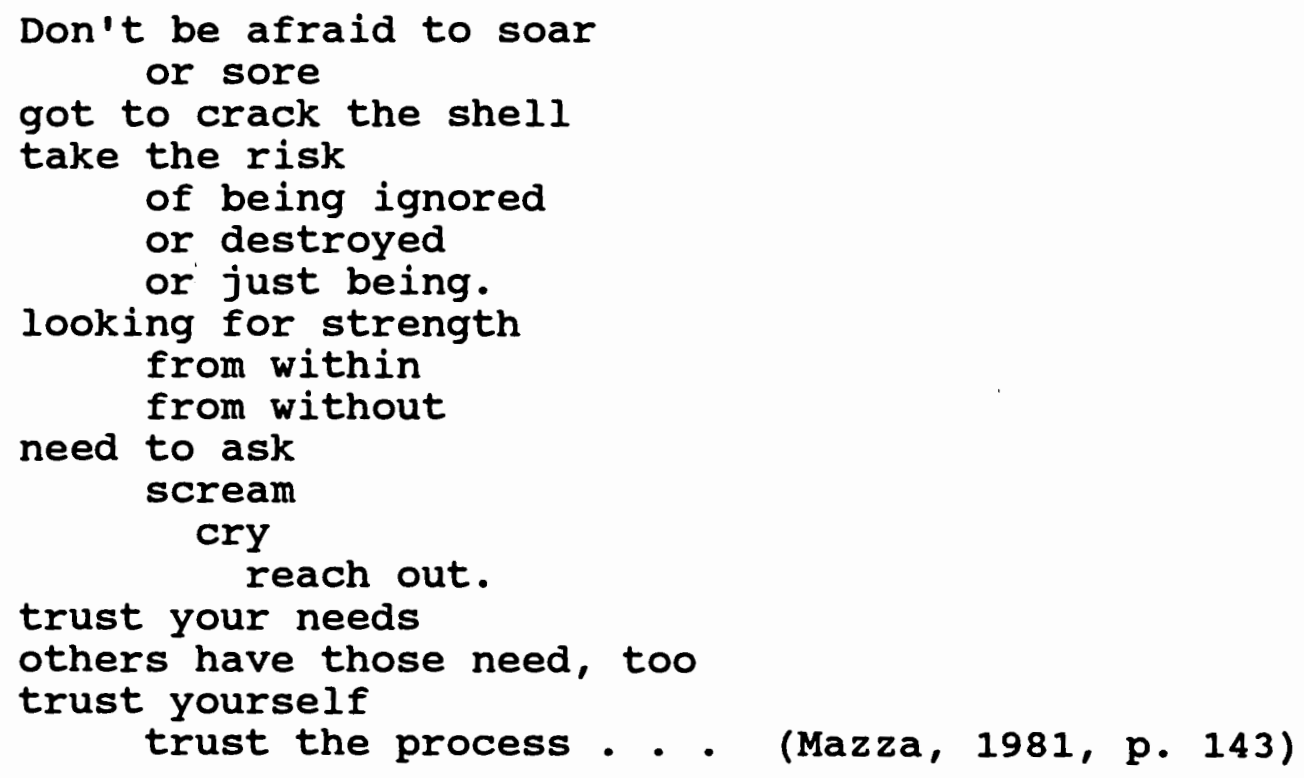


PROPOSED MUSIC THERAPY SESSION FORMAT

\section{Sample Lesson Plan}

The following music therapy intervention is written in a lesson plan format and provides an example of how a session can be developed and implemented by the counselor. It is from the Music Therapy Sourcebook, by Cecilia schulberg (1981), which contains a wide variety of music therapy interventions utilizing many different media and procedures to address a wide spectrum of client populations. purpose of the activity.

1. To present a variety of situations, reactions resulting from these situations, and ways to deal with these situations and reactions;

2. To promote independent thinking and problem solving;

3. To encourage socialization via verbal interaction and cooperation in a group setting; and

4. To provide a positive, productive experience.

Procedure for action. Each group member is given a card describing a realistic life situation. The counselor instructs the client to imagine himself or herself in that particular situation. Each member then selects a song that describes the way he or she might react in the given situation, plays it for the group, and either explains what reaction the song represents or has the group try to guess. Interventions may center on differing and common reactions 
to the same situation, cognitions and feelings due to being in the situation, and ways of dealing with the reactions and situation.

Rules governing action. Same rules for group participation that currently operate within the group. Number of required participants. Three or more. Roles of participants. To imagine one's reaction to a situation, find a song that describes the reaction, and actively participate in the discussions.

Results or payoff. Greater awareness of one's reactions to situations and possible ways in which to deal with both.

Abilities and skills required for action.

1. Cognitive: independent thinking and problem solving;

2. Sensory-motor: the ability to communicate;

3. Affective: the ability to work with others.

Interaction patterns. Intra-individual, aggregate, and intra-group.

Physical setting and environmental requirements. Any setting that is comfortable and available for meeting. Required equipment. An assortment of recordings and a record/tape player.

The above sample offers a format for a counselor to consider and utilize in planning and adapting one's own music therapy interventions. 
Listening to Music: Three

Session Format

The following illustrates how a session involving listening to music might be formatted. This particular example also is a suggested music therapy intervention from Figure 1 for the problem area of client impulsivity.

The counselor decides to implement a three session music therapy component for the group that addresses how one reacts to different music and sounds and how that can influence one's behavior. The group consists of female inmates who, within their therapeutic community, are experiencing high levels of tension and acting out their anger with inappropriate behaviors. They are also new to treatment, so group development is at the beginning stages and trust levels are low. ${ }^{3}$

Session one. The purpose of the first session is for clients to gain awareness of their mood state and how music and sounds might affect that state, either positively or negatively. During the first session, clients check-in by disclosing their current mood state and why they might be feeling that way. The counselor then introduces the concept of sounds and music and their effects on our moods. To demonstrate this, clients are instructed in deep breathing

3 This three session format was developed and used by the author with women incarcerated at Columbia River Correctional Institution who are participating in the Turning Point Alcohol and Drug Program located at the correctional facility. 
techniques and relaxation techniques and asked to practice these as they listen to three different music selections, each of which lasts about five minutes. Feedback from clients was elicited from clients following each selection, and the therapist emphasizes the fact that there are no right or wrong impressions; client viewpoints may vary and all are honored, as all are valid. clients are also encouraged to let themselves freely visualize and be open to any thoughts or feelings that arise from listening to the music.

The first musical selection consists of nature sounds, such as birds, waterfalls, gurgling creeks, frogs and crickets. The second selection is relaxation music. The third selection might be a New Age musical selection that has a slightly faster tempo and utilizes synthesizers and electronic musical sounds. clients share after each session their feelings and visualizations about each selection, and the counselor helps facilitate a discussion and change in awareness about how moods and feelings changed with each selection. The visualizations can sometimes bring up some therapeutic material to work with and be processed before the close of the session that addresses a client's issues. The closing involves a check-in about how moods might be different from the beginning of the session and how that might affect their day differently from when they came in. 
Session two. The second session is designed to deepen clients' awareness about the strong influences of sounds and music, paving the way to discussion about how to use sounds and music to help manage behavior. During this session, clients listen to relaxation music while they create a "record album." The album is a two sided blank piece of construction paper. clients are provided with magazines and art supplies such as markers, colored chalk, colored pencils and asked to create a collage that represents on one side sounds that relax or soothe them, and on the other side sounds that energize or annoy them. The first two thirds of the session involve creation of the album. The last one third is for sharing their work with the group and summarize what they are hearing from each other.

Session three. In this session, the counselor facilitates a discussion on how sounds and/or music affect each client in a positive or negative way. The intervention that takes place is the identification for each client of what sounds or music one might listen to or visualize when involved in an event that triggers her anger. It can then become another stop and think type of cognitive tool to put the client in an emotional state that can be more conducive to the client confronting her issue in a healthy problem solving manner, as emotions and behavior are at a more conscious level of awareness. 
EVALUATION AND SUMMARY

A wide range of music therapy interventions can be utilized with corrections clients in the prison setting. To do so with any breadth or cohesiveness, however, necessitates the implementation of some kind of model that incorporates the theory and use of music therapy as a complementary intervention that becomes part of the larger therapeutic structure. It is this author's recommendation that a model be used that corresponds with common treatment procedures found in the prison setting. That process would provide a guide for steps a counselor would take when working with a client within the prison setting. It consists of intake/assessment, development of treatment plan, consideration of music therapy interventions as part of a client treatment plan, progress reports, and evaluation and termination. At each of these stages, specific steps can be taken that can provide opportunity to consider and/or utilize music therapy as a therapeutic intervention. The key to implementing such a model seems to be: (a) assessing interest and acceptance by therapy staff of music therapy interventions and (b) developing staff awareness of music therapy in general and specific applications in particular, thereby increasing likelihood of such interventions being considered when treatment plans are developed by staff.

Central treatment issues identified for the corrections client in this proposed model fall into the treatment areas 
of self-development, self control and coping skills. Contained in these three areas are issues central to the therapeutic process of client change and easily identifiable in a client's treatment plan, where a decision could be made about whether or not to utilize a music therapy intervention. Key issues where music therapy could be beneficial to the corrections client include developing awareness of emotions and thoughts; developing a more adaptive self concept and corresponding behaviors; reducing anxiety and promoting relaxation; developing stress and anger management skills; developing problem solving skills; and developing behaviors that reflect individual accountability and responsibility.

several music therapy interventions are offered that can address these issues and help facilitate insight and encourage the use of new, adaptive behaviors on the part of the client. Such interventions include improvisational music therapy approaches, various approaches and techniques for listening to music and then encompassing this experience into the therapy session, and composing music or lyrics.

These interventions can be used in individual or group settings and are adaptive for use in different ways, depending on the client and the pertinent issues. The purpose of providing music therapy interventions within the prison setting is to introduce new techniques to enhance current therapeutic work with corrections clients with the 
purpose of continually improving the clients' chances of making positive cognitive, emotional and behavioral changes to promote a successful transition from prison to a longterm existence in the outside world. 
Music therapy is a specialty area within the counseling field that offers an additional and promising approach in working with corrections clients. Sound has always been part of the human experience throughout history; the organized sound that became music probably developed from the imitation of natural sounds. Music has at different times and in different cultures been associated with magic, religion, and healing. The fact that it can affect us in powerful ways seems clear; how it can be used therapeutically is something that continues to be explored. The purpose of this thesis has been to explore the possibilities of utilizing music therapy within the prison inmate population. From the literature and field work already completed by mental health and corrections professionals, and this author's own experience as a counselor in the prison setting, several issues can be identified that are common to both music therapy and the treatment of corrections client. For this reason, and reasons already expressed in this thesis regarding the need for innovative mental health treatment for inmates, music therapy seems to offer a creative, dynamic and results 
oriented method for helping facilitate client change in the corrections population.

It is recommended that music therapy be looked at as a complement to current treatment efforts, and if utilized, be integrated into already existing treatment structures. To familiarize treatment staff as to the availability and uses of music therapy, it is recommended that some kind of inservice training be provided regarding general theories of music therapy and particular music therapy applications, and a curriculum be developed and made available to treatment staff providing specific information on applications that could be useful and utilized by the counselor.

The likelihood of acceptance for music therapy interventions seems based on a particular treatment program's philosophy, philosophy of treatment administrators and managers, and the conditions within the particular treatment setting, as well as individual counselor preferences. Further, if the use of music therapy interventions is incorporated into the therapeutic structure, this author believes it is critical to establish and maintain accountability about the process and outcomes of music therapy interventions through consistent evaluation.

A counselor's effectiveness, regardless of the type of population he or she serves, depends in large part on the counselor's active personal and professional growth through 
continued learning and exploration into new approaches and ideas. It is this author's hope that counselors will contemplate the possibilities of music therapy through exploration into the wide range of therapeutic possibilities that exist in this field. Much can be adapted to the counselor's current theoretical framework, providing new insights and methods to enhance the counselor's work in depthful and meaningful ways.

The lack of documented literature and research in the area of music therapy and the corrections client leads this author to recommend that efforts be undertaken in this area. Much could be gained in the counseling and corrections fields by further exploration into how innovative and powerful interventions such as music can contribute to the development of therapeutic programs that help a corrections client develop adaptive, pro-social behaviors and remain outside of prison once released. All of society could benefit. 
Alvin, J. (1965). Music for the handicapped child. London: Oxford University Press.

Alvin, J. (1966). Music therapy. London: John Baker Publishers, Ltd.

Bandler, R., \& Grinder, J. (1975). The structure of magic (Vol. 1). Palo Alto, CA: Science and Behavior Books.

Bayse, D. (1991). As free as an eagle: The inmate's family survival quide. Laurel, MD: American Correctional Association.

Beaulieu, J. (1987). Music and sound in the healing arts: An energy approach. New York: Station Hill Press.

Bell, J. (1987). Music and the elderly. Educational Gerontology, 13(2), 147-155.

Berne, E. (1964). Games people play. New York: Grove Press.

Boxill, E. (1987). Music therapy for the developmentally disabled. Rockville, MD: Aspen Systems.

Boyum, S. (1978). Therapeutic uses of poetry and music. Journal of College student Personnel, 19, 363 .

Bright, R. (1972). Music in geriatric care. London: Angus and Robertson Ltd.

Bruscia, K. (1987). Improvisational models of music therapy. Springfield, IL: Thomas Books.

Brydon, K. (1979). Musical metaphor as a means of therapeutic communication. Journal of Music Therapy, 16(3), 149-153.

Corey, G. (1986). Theory and practice of counseling and psychotherapy. Pacific Grove, CA: Brooks/Cole.

Corey, G., Corey, M., Callanan, P., \& Russell, J. (1988). Group techniques. Pacific Grove, CA: Brooks/Cole. 
Cripe, F. (1986). Rock music as therapy for children with attention deficit disorder: An exploratory study. Journal of Music Therapy, 23(1), 31-37.

Curtis, S. (1986). The effect of music on pain relief and relaxation of the terminally ill. Journal of Music Therapy, 23(1), 10-24.

Diamond, J. (1979). Behavioral kinesiology. New York: Harper and Row.

Duerksen, G., \& Darrow, A. (1991). Music class for the at risk: A music therapist's perspective. Music Educator's Journal, 78(3), 46-49.

Einstein, A. (1936). A short history of music. New York: oxford University Press.

Ellis, A. (1974). Humanistic psychotherapy: The rational-emotive approach. New York: Julian Press.

Ellis, A., \& Harper, R. (1975). A new quide to rational living. North Hollywood, CA: Wilshire.

Fleshman, B., \& Fryear, K. (1981). Music, the therapeutic experience. New York: Pergaman Press.

Foraker-Thompson, J. (1992). Interaction between criminology theory and practice in the criminal justice field. In A. Walsh, correctional assessment, casework and counseling (pp. 24-25). Laurel, MD: American Correctional Association.

Gammond, P. (1970). The meaning and magic of music. New York: Golden Press.

Gfeller, K. (1987). Music therapy theory and practice as reflected in research literature. Journal of Music Therapy, 24 (4), 178-194.

Giaccobe, G. (1972). Rhythm builds order in brain damaged children. Music Educator's Journal, 20(4), 24-26.

Gladding, S. (1985). Counseling as an art: The creative arts in counseling. Alexandria, VA: American Counseling Press.

Gladding, S. (1988). Counseling: A comprehensive profession. Columbus, OH: Merrill. 
Gladding, S., \& Mazza, N. (1983, March 20-23). Uses of poetry and music in counseling. Paper presented at the annual convention of the American personnel and Guidance Association, Washington, DC.

Glasser, W. (1965). Reality therapy. New York: Harper and Row.

Hal1, F. (1993). Department of corrections overview of 1993-1995 strategic plan. Salem: Oregon Department of Corrections.

Harris, T. (1967). I'm okay--You're okay. New York: Harper and Row.

Heller, G. (1987). Ideas, initiatives, and implementations: Music therapy in America, 1789-1848. Journal of Music Therapy, 24(1), 35-45.

James, M. \& Townsley, R. (1989). Activity therapy services and chemical dependency rehabilitation. Journal of Alcohol and Drug Education, $34(3), 48-53$.

Jennings, S. (Ed.) . (1975). Creative therapy. London: Pitman and Sons, Ltd.

Johnson, J. (1985). Music in the creative lifestyles of the elderly. Unpublished master's thesis, Norfolk state University, Norfolk, VA.

Kalish-Weiss, B. (1989) - Creative arts therapies in an inner city school. Los Angeles: Science and Behavior Books .

Kenny, A. (1987) . Counseling the gifted, creative and talented: An arts activities approach. Gifted Child Today, $10(5), 45-51$.

Kuhn, T., \& Booth, G. (1988). The effect of melodic activity, tempo change, and audible beat on tempo perception of elementary students. Journal of Research in Music Education, 36(3), 140-155.

Lester, D. (1981) - Psychotherapy for offenders. Jonesboro, TN: Pilgrimage.

Lingerman, H. (1983) . The healing energies of music. Wheaton, IL: Theosophical Publishing House.

Maslow, A. H. (1954). Motivation and personality. New York: Harper and Brothers. 
Mazza, N. (1981). The use of poetry and music in treating the troubled adolescent. Adolescence, 16(62), 403-408.

Meeker, A. (1985). Empty Lizzie: Using the expressive arts as a tool for dealing with anger. Creativity and the Arts in special Education, 29(3), 31-34.

Moreno, J. (1980). Musical psychodrama: A new direction in music therapy. Journal of Music Therapy, 17(1), 34-42.

Nordoff, P., \& Robbins, C. (1965). Music therapy for handicapped children. New York: Steiner.

Palmer, M. (1985, November 6). Expressive therapists in long-term care settings. Paper presented at the national conference of the American Association for Adult and Continuing Education, Milwaukee, WI.

Perls, F. S. (1974). Gestalt therapy verbatim. New York: Bantam Books.

Peters, T. (1987). Music: An ancillary technique in therapy. American Journal of Family Therapy, 9 (1), 53-57.

Priestley, M. (1975). Music therapy in action. London: Constable and Company Ltd.

Ragghianti, M. \& Glenn, T. (1991) - Reducing recidivism: Treating the addicted inmate. Center City, MN : Hazelden.

Robbins, A. (Ed.) . (1980) . Expressive therapy. New York: Human Sciences Press, Inc.

Rogers, C. (1957) . Client centered therapy. New York: Houghton Mifflin.

Rouget, G. (1985). Music and trance. Chicago: University of Chicago Press.

Samenow, S. (1984). Inside the criminal mind. New York: Times Books.

Samenow, S. (1989). Before it's too late. New York: Times Books.

Santiago, P. (1969). Beginnings. Baltimore, MD: Baltimore Press. 
Schneider, M. (1956). Primitive Music. In New Oxford history of music (pp. 39-62). New York: Oxford University Press.

Schoen, M. (1940). The psychology of music. New York: The Ronald Press Co.

Schulberg, c. (1981). The music therapy sourcebook. New York: Human Sciences Press.

Schullian, D. (1948). Music and medicine. New York: Henry Schuman, Inc.

scott, c. (1900). Music: Its secret influence throughout the ages. Philadelphia: The David McKay Company.

Severin, R. (1965). Humanistic viewpoints in psychology. New York: McGraw-Hill.

Storr, A. (1992).. Music and the mind. New York: Ballantine Books.

Sykes, G. (1967) . Crime and society. New York: Random House.

Walsh, A. (1992). Correctional assessment, casework, and counseling. Laurel, MD: American Correctional Association.

Walter, B. (1957). of music and music making. New York: Norton and Company.

Watson, M. (1987). Healing music. New York: Avery Publishing Group.

Watzlawick, P. (1978). The language of change. New York: Basic Books.

Yochelson, S. \& Samenow, S. (1986). The criminal personality, volume III: The drug user. North vale, NJ: Jason Aronson.

Zinker, J. (1978). Creative process in gestalt therapy. New York: Vintage Books. 